\title{
Impact of COVID-19 outbreak on the mental health status of undergraduate medical students in a COVID-19 treating medical college: A prospective longitudinal study
}

\author{
Ilango Saraswathi ${ }^{\text {Equal first author, } 1}$, Jayakumar Saikarthik ${ }^{\text {Corresp., } 2}$, K Senthil Kumar ${ }^{\text {Equal first author, } 1}$, Kumar Madhan Srinivasan \\ ${ }^{3}$, M Ardhanaari $^{4}$, Raghunath Gunapriya ${ }^{5}$ \\ ${ }^{1}$ Department of Physiology, Madha Medical College and Research Institute, Chennai, Tamil nadu, India \\ 2 Department of Basic Medical Sciences, Majmaah University, Ar- Riyadh, Saudi Arabia \\ 3 Department of General Medicine, Madha Medical College and Research Institute, Chennai, Tamil nadu, India \\ 4 Department of Psychiatry, Meenakshi Medical College Hospital and Research Institute, Enathur, Tamil nadu, India \\ 5 Department of Anatomy, Saveetha Medical College Hospital, Thandalam, Tamil nadu, India \\ Corresponding Author: Jayakumar Saikarthik \\ Email address: s.jaya@mu.edu.sa
}

Background. COVID-19 pandemic is found to affect the mental health of the population. Undergraduate medical students are especially prone to mental health disorders and hence could be more vulnerable to the impact of the pandemic.

Methods. A prospective longitudinal study was conducted on 217 undergraduate medical students in a medical college at Chennai, India. Depression, anxiety, and stress levels were recorded using Depression Anxiety Stress Scale 21 Items (DASS21) before and during COVID-19 outbreak in India in December 2019 and June 2020 respectively. In the follow-up survey, in addition to DASS21, Pittsburgh Sleep Quality Index to assess sleep quality and a self-administered questionnaire to assess the impact of COVID-19 related stressors were used. The self administered questionnaire assessed the status of COVID-19 testing, interactions with COVID-19 patients, self-perceived levels of concerns and worries related to academics [COVID-19-AA (academic apprehensions)] and those pertaining to the self and family/friends [COVID-19GA (general apprehensions)]. Cross-sectional and longitudinal comparison of overall scores of depression, anxiety, and stress and scores stratified by gender, year of study, place of residence and monthly family income were performed. Predictors for depression, anxiety, and stress during COVID-19 were investigated using adjusted binary logistic regression analysis and results were expressed as adjusted odds ratio with $95 \%$ confidence interval $(\mathrm{Cl})$. A P value $<0.05$ was considered statistically significant.

Results. The average scores for depression, anxiety, and stress during the baseline survey were $7.55 \pm 7.86,4.6 \pm 6.19$ and $7.31 \pm 7.34$ with the prevalence $(95 \% \mathrm{Cl})$ of $33.2 \%(27-39.9 \%), 21.2 \%$ (16-27.2\%) and $20.7 \%$ (15.5-26.7\%); in follow-up survey, the mean scores were 8.16 $\pm 8.9,6.11 \pm 7.13$ and $9.31 \pm 8.18$ with $35.5 \%$ (29.1-42.2\%), 33.2\% (27-39.9\%) and 24.9\% (19.3-31.2\%) of the study population showing symptoms of depression, anxiety, and stress respectively. There was a significant increase in both the prevalence and levels of anxiety and stress $(\mathrm{P}<0.001)$, with depression remaining unchanged during COVID-19, irrespective of gender, year of study, place of residence and family's monthly income. Poor sleep quality, higher levels of baseline depression, anxiety, and stress, higher COVID-19-GA, absence of COVID-19 patients in family/friends and direct interactions with COVID-19 patients were found to be significant predictors of negative mental health in undergraduate medical students. COVID-19-AA was not significantly associated with depression, anxiety, and stress.

Peer) reviewing PDF | (2020:08:51660:2:0:NEW 18 Sep 2020) 
Conclusion. COVID-19 pandemic appears to negatively affect the mental health of the undergraduate medical students with the prevalence and levels of anxiety and stress being increased, and depression symptoms remaining unaltered. Addressing and mitigating the negative effect of COVID-19 on the mental health of this population is crucial. 


\section{Impact of COVID-19 outbreak on the mental health}

2 status of undergraduate medical students in a COVID-

319 treating Medical College: A prospective

4 longitudinal study

5

6

7 8

9

10

Saraswathi Ilango ${ }^{1}$, Saikarthik Jayakumar ${ }^{2}$, Senthil Kumar K ${ }^{1}$, Madhan Srinivasan Kumar ${ }^{3}$, Ardhanaari $\mathrm{M}^{4}$, Gunapriya Raghunath ${ }^{5}$

${ }^{1}$ Department of Physiology, Madha Medical College \& Research Institute, Chennai, Tamil Nadu, India

${ }^{2}$ Department of Basic Medical Sciences, Majmaah University, Ar Riyadh, Kingdom of Saudi Arabia

${ }^{3}$ Department of General Medicine, Madha Medical College \& Research Institute, Chennai, Tamil Nadu, India

${ }^{4}$ Department of Psychiatry, Meenakshi Medical College Hospital \& Research Institute, Enathur, Tamil Nadu, India

${ }^{5}$ Department of Anatomy, Saveetha Medical College \& Hospital, Thandalam, Tamil Nadu, India

Corresponding Author:

Saikarthik Jayakumar ${ }^{2}$

Department of Basic Medical Sciences

Majmaah University, Ar Riyadh,

Kingdom of Saudi Arabia

Email address: s.jaya@mu.edu.sa 
38

39

40

41

42

43

44

45

46

47

48

49

50

51

52

53

54

55

56

57

58

59

60

61

62

63

64

65

66

67

68

69

70

71

72

73

74

75

76

77

78

79

80

\section{Abstract}

Background. COVID-19 pandemic is found to affect the mental health of the population. Undergraduate medical students are especially prone to mental health disorders and hence could be more vulnerable to the impact of the pandemic.

Methods. A prospective longitudinal study was conducted on 217 undergraduate medical students in a medical college at Chennai, India. Depression, anxiety, and stress levels were recorded using Depression Anxiety Stress Scale 21 Items (DASS21) before and during COVID19 outbreak in India in December 2019 and June 2020 respectively. In the follow-up survey, in addition to DASS21, Pittsburgh Sleep Quality Index to assess sleep quality and a selfadministered questionnaire to assess the impact of COVID-19 related stressors were used. The self administered questionnaire assessed the status of COVID-19 testing, interactions with COVID-19 patients, self-perceived levels of concerns and worries related to academics [COVID19-AA (academic apprehensions)] and those pertaining to the self and family/friends [COVID19-GA (general apprehensions)]. Cross-sectional and longitudinal comparison of overall scores of depression, anxiety, and stress and scores stratified by gender, year of study, place of residence and monthly family income were performed. Predictors for depression, anxiety, and stress during COVID-19 were investigated using adjusted binary logistic regression analysis and results were expressed as adjusted odds ratio with 95\% confidence interval $(\mathrm{Cl})$. A P value $<0.05$ was considered statistically significant.

Results. The average scores for depression, anxiety, and stress during the baseline survey were $7.55 \pm 7.86,4.6 \pm 6.19$ and $7.31 \pm 7.34$ with the prevalence $(95 \% \mathrm{Cl})$ of $33.2 \%(27-39.9 \%)$, $21.2 \%(16-27.2 \%)$ and $20.7 \%(15.5-26.7 \%)$; in follow-up survey, the mean scores were $8.16 \pm 8.9,6.11 \pm 7.13$ and $9.31 \pm 8.18$ with $35.5 \%(29.1-42.2 \%), 33.2 \%(27-39.9 \%)$ and $24.9 \%$ (19.3-31.2\%) of the study population showing symptoms of depression, anxiety, and stress respectively. There was a significant increase in both the prevalence and levels of anxiety and stress $(P<0.001)$, with depression remaining unchanged during COVID-19, irrespective of gender, year of study, place of residence and family's monthly income. Poor sleep quality, higher levels of baseline depression, anxiety, and stress, higher COVID-19-GA, absence of COVID-19 patients in family/friends and direct interactions with COVID-19 patients were found to be significant predictors of negative mental health in undergraduate medical students. COVID-19-AA was not significantly associated with depression, anxiety, and stress.

Conclusion. COVID-19 pandemic appears to negatively affect the mental health of the undergraduate medical students with the prevalence and levels of anxiety and stress being increased, and depression symptoms remaining unaltered. Addressing and mitigating the negative effect of COVID-19 on the mental health of this population is crucial.

Keywords: COVID-19, Undergraduate medical students, Longitudinal study, Mental health, Depression, Anxiety, Stress, Sleep quality, DASS21, PSQI 


\section{Introduction}

82 The World Health Organization (WHO) announced COVID-19 outbreak initially, as a public

83

84

85

86

87

88

89

90

91

92

93

94

95

96

97

98

99

100

101

102

103

104

105

106

107

108

109

110

111

112

113

114

115

116

117

118

119

120 health emergency of international concern (PHEIC) on January 30, 2020 and later declared as a pandemic on March 11, 2020 (WHO 2020). In India, the first COVID-19 case was reported in Kerala on January 30, 2020, and by May 19, the number of cases had crossed one hundred thousand. By September 7, India became the world's second worst hit nation with 4.2 million confirmed COVID-19 cases following United States of America and has recorded 71,642 deaths (Times, 2020). Within India, the state of Maharashtra was the worst hit state followed by Andhra Pradesh and Tamil Nadu, contributing to $21.6 \%, 11.8 \%$ and $11 \%$ of the total cases respectively (Newsdesk, 2020). The Government of India declared a nationwide lockdown on 25th March 2020, as a measure to mitigate the spread of infection. However, prolonged lockdown is not only unfavorable to the individuals, it also significantly affects the nation's economy. As a way to revive and restore the affected economy, a phase-wise upliftment of lockdown was announced from June 1, easing of some restrictions, while the lockdown was maintained for the containment zones alone.

Public health emergencies during epidemic/pandemic like SARS, MERS and Ebola outbreak were associated with increased psychological distress in the affected population (Batawi et al. 2019; Lee et al. 2007; Lotsch et al. 2017). Maladaptive behaviors, emotional and defensive reactions were some of the psychological responses to pandemic (Taylor 2019). Social isolation was found to be strongly associated with anxiety, depression, self-harm, and suicidal tendencies (Matthews et al. 2019). Studies indicated that social distancing for a longer duration could affect the mental health negatively (Reynolds et al. 2008). Isolation, boredom, frustrations, worries about contracting the infection, lack of freedom, concerns for family/friends are some of the factors that could affect mental well-being during quarantine (Brooks et al. 2020). Poor sleep quality and increased psychological distress were also well-documented during earlier pandemics (Chen et al. 2006; Johal 2009). In particular, poor sleep was associated with negative emotions, depressive symptoms and increased the risk of mental illness (Agargun \& Kara 1997; Tao et al. 2017).

In a recent study conducted during COVID-19 outbreak in India, one fifth of adults were found to suffer from depression and stress and one fourth from anxiety (Saikarthik et al. 2020). Mental health of medical students was found to be even poorer, when compared to general population (Bergmann et al. 2019). Medical education is the most demanding of all the other professional programs in terms of both academics and emotional component of the students (Wolf 1994). Globally, one in three medical students were found to have anxiety, which was higher than the general population (Tian-Ci Quek et al. 2019). Level of depression, suicidal ideation, suicide rates, substance abuse and mental health disorders were also found to be higher among medical students (Hays et al. 1996; Molodynski et al. 2020; Schwenk et al. 2010). Although medical students have better access to mental health care, they were less likely to seek mental health help 
121 compared to general population, mainly due to stigma surrounding mental health disorders. This

122 may lead to untoward and harmful coping methods like excess alcohol consumption and

123 substance abuse (Chew Graham et al. 2003; Rosenthal \& Okie 2005).

124

125

126

127

128

129

130

131

132

133

134

135

136

137

138

139

140

141

142

143

144

145

146

147

148

149

150

151

152

153

154

155

156

157

158

159

Swine flu (H1N1) outbreak in 2009 was the last outbreak of an infectious disease in a pandemic scale to which India was exposed (WHO 2009). Undergraduate medical students in India are usually in the age group of late teens to mid-twenties, and hence the current COVID-19 infection is the first exposure to them as adults on a pandemic level. In addition, medical students are facing challenges such as sudden changes in their training routine, including teaching and assessment via online sessions, decreased patient contact and interactions with peers to name a few. These changes result in increased screen time, possible hinderance to their training and increased risk of contracting the infection mainly among the students in clinical postings. All these factors could eventually exert a toll on the mental and emotional well-being of the medical students as they are on an unknown territory.

Earlier studies show that the negative impact of epidemic/pandemic on the mental health are higher in healthcare workers (Lee et al. 2018; Lu et al. 2006; McAlonan et al. 2007).

Unfortunately, only limited studies were done on the impact of epidemic/pandemic on the mental health of medical students. Studies on the impact of COVID-19 pandemic on medical students are limited to cross-sectional surveys assessing attitude, awareness, knowledge, precautionary measures, concerns, risk perceptions, impact on education and confidence, and fear of COVID19 (Agarwal et al. 2020; Ahmed et al. 2020b; Choi et al. 2020; Khasawneh et al. 2020; Nguyen et al. 2020; Taghrir et al. 2020). Literature search showed only a single study about the psychological impact of COVID-19 on medical students, which cross-sectionally assessed their anxiety levels (Cao et al. 2020).

Globally, few longitudinal studies compared mental health before and during COVID-19, and found an increase in anxiety and depression symptoms in college students in China (Li et al. 2020a), the United States (Huckins et al. 2020) and a deterioration of mental health in the general population in the United Kingdom (Pierce et al. 2020). To our knowledge, there are no studies analyzing the impact of COVID-19 on mental health of undergraduate medical students prospectively to assess cause and relationship. From these observations, we hypothesized that COVID-19 outbreak and quarantine would have a serious negative impact on the mental health of undergraduate medical students. Hence, we conducted a prospective longitudinal study to investigate the mental health of undergraduate medical students over a duration of 6 months by analyzing data collected before and during COVID-19 outbreak in India. The study was conducted in a medical college in Chennai, Tamil Nadu, which is a center for treating COVID19 patients. We did an extensive investigation of possible confounders and predictors of mental health disorders including demographics, sleep quality, apprehensions related to and caused by

Peer) reviewing PDF | (2020:08:51660:2:0:NEW 18 Sep 2020) 
160

161

162

163

164

165

166

167

168

169

170

171

172

173

174

175

176

177

178

179

180

181

182

183

184

185

186

187

188

189

190

191

192

193

194

195

196

197

198

COVID-19 in terms of academics and concerns for the self, family, friends, and interpersonal relationships.

\section{Materials \& Methods}

\section{Participants and setting}

The study was originally planned to be a cross-sectional survey for assessing the mental health of the undergraduate medical students in the institution. There were 300 medical students in the institution enrolled for undergraduate medical degree. The Bachelor of Medicine and Bachelor of Surgery (M.B.B.S) is a 5.5 years undergraduate medical course offered in India in which the first 2.5 years concentrate mostly on basic medical sciences (pre and para-clinical subjects) and the next 2 years on clinical subjects followed by 1 year of Compulsory Rotatory Resident Internship (CRRI). All 300 students studying in pre-clinical (1st year), para-clinical (1.5 years after preclinical year) and clinical years (pre-final year, final year, and resident interns) were included for the study and convenience sampling method was used. The students were explained about the objective of the study and were informed that the participation was voluntary, and confidentiality will be maintained. 276 students out of the total 300 students agreed to take part in the study from whom written consent was obtained before the beginning of the study.

\section{Baseline (Before COVID-19) survey}

Basic sociodemographic details such as age, gender, year of study, area of current residence and family gross monthly income were collected, and the mental health status was assessed using Depression Anxiety Stress Scale 21 items (DASS21). Students below 18 years of age and those with self-reported history of any pre-existing chronic medical conditions including mental health disorders were excluded ( 5 were underage and 2 reported history of bronchial asthma). The remaining 269 participants who were included for the study were contacted during their free time, after classes and were encouraged to answer the survey sincerely and doubts were clarified. Email id and mobile number were collected from all the participants. This part of the study was conducted during the first two weeks of December 2019, which was before COVID-19 outbreak in India.

\section{Follow-up (During COVID-19) survey}

With the unexpected changes to normalcy caused by the COVID-19 outbreak and subsequent lockdown, the authors decided to prospectively study the mental health status of the medical students to assess the effects of COVID-19 on mental health of the study population. After obtaining permission from Institutional Ethics Committee (IEC), the original data from the crosssectional study was decided to be taken as 'before COVID-19 data' (baseline) and another survey was conducted on June 2020 (June 10 to 20) to collect 'during COVID-19' data (followup). 
199 The follow-up survey was conducted via Google form whose link was sent through personal 200 email IDs of the students which were collected during the baseline survey. This protocol was 201 exercised in order to follow strict social distancing protocol and to avoid direct contact. The 202 follow-up survey included 5 sections; first section had a detailed description of the purpose of 203 the study, along with the informed consent. This section explained the importance and benefits of 204 the survey in the current pandemic, highlighting the voluntary nature of participation and 205 assurance of confidentiality of the collected data. Only after consenting to the study, the 206 participants could access the remaining sections. The successive sections collected responses for 207 demographic details, self-administered questionnaire, DASS21 and Pittsburgh Sleep Quality 208 Index (PSQI). Out of the 269 participants from the baseline survey, 30 randomly selected 209 students were included in a pilot study (described below) and were hence excluded from the 210 follow-up survey. Out of the remaining 239 participants, 222 students responded, from which 5 211 responses were excluded because of being incomplete (response rate 90.8\%). The final sample 212 size of this prospective longitudinal study was 217. A flowchart illustrating the sample selection 213 from baseline to follow-up survey is shown in Figure 1.

214

215

216

217

218

219

220

221

222

223

224

225

226

227

228

229

230

231

232

233

234

235

236

237

238

\section{Survey instruments}

To fulfil the objective of our longitudinal study, besides DASS21, 'during COVID-19' data also included a self-administered questionnaire to assess the impact of COVID-19 related stressors and PSQI to assess the sleep quality of the students.

\section{Assessment of the impact of COVID-19 related stressors}

A self-administered questionnaire was prepared by the authors after an extensive literature search, discussion with peers and local experts (Wang et al. 2020; Wong et al. 2007). It included 12 close-ended questions out of which, Items 1-3 focused on the subjects' status of COVID-19 testing (Yes/No) and their interactions with COVID-19 patients (Yes/No/I don't know). The remaining nine items were designed to assess self-perceived levels of concerns and worries for the self (4-6) and family/friends (7-8) and those related to academics (9-12), due to COVID-19 outbreak and quarantine (Supplemental file- Other). The responses were measured on a Likert scale of score 1 to 5 , with 1 being the least and 5 being the maximum. This questionnaire was first tested empirically on 30 students (15 each from pre/para clinical years and clinical years) as a pilot study (Hill \& century 1998). The collected feedback and responses were analyzed, and corrections were made in the form of changes in articulation and simplification of vocabulary with the help of experts in this field.

\section{Identification of latent variables from the self-administered questionnaire}

An exploratory factor analysis (EFA) was performed on the 9 items (item 4-12) to determine the validity of the questionnaire and to identify latent variables that could enable the objective of the study. The EFA was conducted using principal component analysis with varimax rotation for factor extraction. 
239 The extracted factors were analyzed for retention using Kaiser criterion (Eigen value $>1$ ), Scree

240 test and counter-validated using parallel analysis. The Eigen values obtained from parallel

241 analysis, which are values generated randomly with the same number of variables and sample

242 size, were compared with the factor solution generated by EFA with our data. Eigen values of the

243 factors that were higher than the values obtained from parallel analysis decided the number of

244 factors. The two-factor solution thus obtained had 5 items in one (items 4-8) and 4 items in

245 another (items 9-12). The factors were named COVID-19-related general apprehensions

246 (COVID-19-GA) and COVID-19-related academic apprehensions (COVID-19-AA) respectively

247 (Table S1). Reliability analysis was performed for each of the factors separately which presented

248 with a high reliability, with the Cronbach's alpha score of 0.89 for COVID-19-GA and 0.91 for

249 COVID-19-AA. COVID-19-GA was scored by totaling the scores of the five individual items

250 with the total score ranging from 5 to 25 and higher scores denote higher general apprehension.

251 Similarly, COVID-19-AA was scored by summing up the scores of the four individual items

252 with the scores ranging from 4 to 20 and higher scores denote higher academic related

253 apprehension.

254

255

256

\section{Estimation of mental health status}

257

Mental health status of the medical students was assessed using Lovibond and Lovibond's

258

Depression Anxiety Stress Scale 21 items (DASS21) (Lovibond et al. 1995). This scale

259 comprises of 21 items with seven each for depression, anxiety, and stress subscales. The total sub scores range from 0 to 42 and is categorized into normal, mild, moderate, severe, and extremely

260 severe. In this study, DASS21 sub scores were categorized dichotomously, with the participants

261 being divided in to those who showed symptoms of depression, anxiety and stress and those who

262 did not, based on the cut-off sub-scores of 9, 7 and 14 respectively (Cheung et al. 2015;

263 Lovibond et al. 1995).

264

265

\section{Estimation of sleep quality}

266

267

Subjective sleep quality was assessed using Pittsburgh Sleep Quality Index (PSQI) which

268 includes 21 items that assess seven components viz. subjective sleep quality, sleep duration, sleep latency, habitual sleep efficiency, use of sleep medications, sleep disturbance, and daytime

270 dysfunction over the duration of two weeks prior to assessment. Global PSQI scores are obtained

271 by summing up the seven individual sub scores and it ranges from 1 to 21 with higher scores

272 (>5) denoting poor sleep quality (Buysse et al. 1989; Rahe et al. 2015).

273

Previous studies have shown high reliability of both DASS21 and PSQI among Indian

274 undergraduate medical student population (Shad et al. 2015; Yadav et al. 2016). In our study,

275

276 both the scales showed good internal consistency and DASS21 scale demonstrated good testretest reliability. Cronbach alpha score for reliability for PSQI was 0.72 and for DASS21 scale

2770.94 (depression subscale 0.85 , anxiety subscale 0.84 , stress subscale 0.87 ) and 0.94 (depression 
278 subscale 0.87 , anxiety subscale 0.81 , stress subscale 0.85 ) for baseline and follow-up survey, 279 respectively.

280

281

282

Ethical consideration

283

284

Ethical approval was obtained from the IEC, Madha Medical College and Research Institute in

285

286

Chennai (MMCRI/IEC/H/018/2020) and research was done in accordance with the Helsinki Declaration for research on human participants.

287

288

\section{Statistical analysis}

Descriptive statistics was performed for all the variables. The scores of depression, anxiety, stress, and sleep quality were expressed as mean \pm standard deviation (SD). Initially, unadjusted univariate association between the demographic variables and depression, anxiety and stress were performed. Mann Whitney U test and Kruskal Wallis test for continuous variables and Chisquare test for categorical variables were used for cross-sectional analysis. Wilcoxon signed rank test for continuous variables and McNemar's test for categorical variables were used for longitudinal analysis. Spearman's correlation test was performed to assess the correlation between the scores obtained from the survey instruments in both the surveys. To explore the contributory factors associated with depression, anxiety, and stress during COVID-19 outbreak (dependent variable), adjusted binary logistic regression analysis was performed. Independent variables included were scores of PSQI, COVID-19-GA, COVID-19AA, dependent variable from baseline survey (depression, anxiety and stress sub-scores in respective regression models) as covariates (continuous variables) and responses for the items 13 from the self-administered questionnaire as independent factors (categorical variables). Crosssectional association between sleep quality and study parameters were analyzed using adjusted binary logistic regression. The effect of each of the independent variable was adjusted for sociodemographic variables which were considered to be potential confounders viz. age, gender, year of study, current residence, and family monthly income, in separate binary regression models. The results were expressed as adjusted odds ratio (aOR), 95\% confidence interval (95\% $\mathrm{CI}$ ) and $\mathrm{P}$ value (statistical significance set at two-tailed $\mathrm{P}<0.05$ ).

\section{Results}


311 This longitudinal study includes 217 undergraduate medical students (78 males and 139

312 females); the average age was $20 \pm 1.6$ years. 5.1\% got tested for COVID-19, and they all tested 313 negative. $14.3 \%$ had friends and family who tested positive for COVID-19 and 12\% declared to

314 have had direct contact with COVID-19 patients (Figure 2). The distribution of responses to the 315 items of COVID-19-GA and COVID-19-AA is shown in Figure 2 and percentage distribution of 316 depression, anxiety and stress in baseline and follow-up survey and PSQI in follow-up survey is 317 shown in Figure 3.

318

319

320

Cross-sectional relationship between sociodemographic variables and depression, anxiety, and stress

321 The cross-sectional and longitudinal relationship between sociodemographic variables and 322 depression, anxiety, and stress are shown in Table 1. There was no significant cross-sectional 323 relationship between the demographic variables and both baseline and follow-up depression, 324 anxiety, and stress scores except in the baseline survey where depression levels were higher in 325 the students from rural sector than urban sector $(\mathrm{P}=0.039)$. The association between demographic 326 variables and depression, anxiety, and stress analyzed by binary logistic regression showed that 327 age was a protective factor for depression in the follow-up survey (OR $0.737,95 \%$ CI 0.565 328 0.961) (Table S2). Other than this, there were no significant associations between demographic 329 variables and mental health in both baseline and follow-up survey (Tables S2-4).

330

\section{Comparison of baseline and follow-up depression, anxiety and stress stratified by} sociodemographic variables

The overall prevalence (with 95\% confidence interval) of depression, anxiety and stress before COVID-19 was 33.2\% (27-39.9\%), 21.2\% (16-27.2\%) and 20.7\% (15.5-26.7\%) and during COVID-19 outbreak was 35.5\% (29.1-42.2\%), 33.2\% (27-39.9\%) and 24.9\% (19.3-31.2\%) respectively. There was a significant increase in the prevalence and mean scores of anxiety and stress when compared to baseline scores $(\mathrm{P}<0.001)$ (Table 1). In terms of prevalence, when compared to baseline values, the prevalence of anxiety was significantly increased during COVID-19 in females $(\mathrm{P}=0.003)$, pre-clinical, para-clinical $(\mathrm{P}=0.014)$ and clinical year students $(\mathrm{P}=0.019)$, students from urban residence $(\mathrm{P}=0.005)$ and those with gross family income above 100,000 INR per month $(\mathrm{P}=0.007)$. In terms of mean DASS21 scores, there was a statistically 
342 significant increase in anxiety with mild effect size and stress levels with moderate to strong

343 effect size in medical students in the follow-up survey compared to baseline levels irrespective of

344 gender, year of study, current residence and gross family income per month (below 50,000 INR

345 and above 100,000 INR) $(\mathrm{P}<0.05)$. Out of the entire study population, the levels of depression

346 have increased significantly in male students and students from urban residence when compared

347 to before COVID-19 levels albeit with mild effect size (Table 1).

348

349

350

351

352

353

354

355

356

357

358

359

360

361

362

363

364

365

366

367

368

369

370

\section{Difference in ranks of DASS21 scores between baseline and follow-up survey}

The difference in ranks of DASS21 scores between baseline and follow-up survey is shown in Table 2. There was no significant change in depression $(\mathrm{P}=0.146)$ in medical students between the two surveys; however, anxiety and stress has increased $(\mathrm{P}<0.001)$, showing an increase in median scores in the follow-up survey (Tables 1,2). The incidence of depression, anxiety, and stress based on DASS21 sub-scores were found to be 2.3 (5 out of 217), 11.98 (26 out of 217) and 4.15 (9 out of 217) per 100 per 6 months, respectively. 97 (44.7\%), 89 (41.01\%) and 142 (65.44\%) students scored higher in depression, anxiety, and stress in the follow-up survey when compared to their responses before COVID-19 outbreak. While 60 (28.04\%), 69 (31.79) and 7 (3.22\%) students scored lesser in depression, anxiety, and stress in follow-up survey (Table 2).

\section{Correlation between the scores of the survey instruments from baseline and follow-up} survey

The results of Spearman correlation analysis of the scores of the survey instruments from baseline and follow-up survey is shown in Table 3 . There were significant positive correlations between PSQI and baseline and follow-up depression, anxiety, and stress. The correlation between the baseline and follow-up depression, anxiety, and stress scores indicates that a higher baseline score was associated with higher follow-up score and vice versa $(\mathrm{P}<0.001)$. There was a relatively weak, but significant positive correlation between depression levels before COVID-19 and COVID-19-related general apprehensions ( $\mathrm{r}=0.152, \mathrm{P}=0.025)$ (Table 3$)$.

\section{Adjusted binary logistic regression analysis of sleep quality}


371 Cross-sectional association between sleep quality and mental health in the follow-up survey is

372 shown in Figure 4. Students with higher depression, anxiety, and stress scores during COVID-19

373 outbreak were found to be more likely to have poor sleep quality $(\mathrm{P}<0.001)$.

374

\section{Adjusted binary logistic regression analysis of follow-up depression, anxiety, and stress}

376

377

378

379

380

381

382

383

384

385

386

387

388

389

390

391

392

393

394

395

396

397

398

399

400

401

402

403

404

405

406

407

The results of binary logistic regression analysis for follow-up depression, anxiety, and stress are shown in Figures 5-7. Poor sleep quality was found to be significantly associated with an increase in depression, anxiety, and stress $(\mathrm{P}<0.001)$. Higher baseline scores of depression, anxiety, and stress were associated with higher levels of the same in follow-up survey $(\mathrm{P}<0.001)$. Higher COVID-19-related general apprehension was associated with higher levels of anxiety $(\mathrm{P}=0.016)$, and stress $(\mathrm{P}=0.005)$. Students who did not have any direct interactions with COVID19 patients were found to be less likely to have symptoms of depression ( $\mathrm{P}=0.017)$ and stress $(\mathrm{P}=0.004)$ when compared to those who did. Similarly, absence of COVID-19 patients in family and friends was found to be associated with decreased levels of stress $(\mathrm{P}=0.004)$.

\section{Discussion}

The present study investigated the mental health status of undergraduate medical students in a medical college, which is a government-approved center for treating COVID-19 patients. The medical college is in Chennai, TamilNadu, which is one of the top 5 COVID-19 affected metropolitan cities in India. Longitudinal data analysis was used to test our hypothesis that COVID-19 outbreak and quarantine has a negative impact on the mental health of undergraduate medical students.

We found that $35.5 \%$ (95\% CI $29.1-42.2 \%), 33.2 \%$ (95\% CI $27-39.9 \%)$ and $24.9 \%$ (95\% CI $19.3-31.2 \%$ ) of the undergraduate medical students, including resident interns showed symptoms of depression, anxiety, and stress respectively during COVID-19 outbreak with the majority with moderate depression (15.2\%), moderate anxiety (17.5\%), and mild stress (13.4\%). Based on the severity ranking, subjects with moderate and above ranking may present with a possible problem that may require intervention (Crawford \& Henry 2003; Lovibond et al. 1995; Page et al. 2007; Stormon et al. 2019). In this study, $23.9 \%, 26.7 \%$ and $11.5 \%$ of the study population presented with moderate to extremely severe levels of depression, anxiety, and stress respectively (Figure 3 ). The six-month incidence of anxiety was found to be comparatively higher (11.98\%) followed by stress $(4.15 \%)$ and depression (2.3\%). There were no other longitudinal studies conducted in medical students during COVID-19 pandemic assessing the incidence of mental health disorders; however, a study conducted in the general public in China found the one-month incidence of mental health disorders to be relatively low (Yali et al. 2020). Though the incidence rate seemed to be relatively low in our study, $44.7 \%, 41.01 \%$ and $65.44 \%$ of the study population scored 
408 higher in depression, anxiety, and stress sub scores during COVID-19 (Table 2). When compared 409 to baseline survey that was recorded before COVID-19 outbreak in India, there was a significant 410 increase in prevalence and levels of anxiety and stress, while that of the depression remained 411 unchanged during COVID-19. Similar studies conducted longitudinally in college students found 412 a significant increase in depression and anxiety when compared to before COVID-19 levels. (Li 413 et al. 2020a, Huckins et al. 2020). This negative impact of the pandemic could be attributed to 414 sudden challenges faced by the medical students in terms of academics, uncertainties about 415 future, fear of infection, news about shortage of personal protective equipment, quarantine

416

417

418

419

420

421

422

423

424

425

426

427

428

429

430

431

432

433

434

435

436

437

438

439

440

441

442

443

444

445

446

447 induced boredom, frustrations, lack of freedom, and fears caused by rumors and misleading news in the media (Bao et al. 2020; Ferrel \& Ryan 2020).

Investigation of the influence of demographics on mental health showed that the increase in anxiety and stress levels in our study population was not affected by gender, year of study, current residence, or family income. We also found no significant cross-sectional difference in depression, anxiety, and stress between the groups of demographic variables during COVID-19. Binary logistic regression analysis of anxiety and stress and demographic variables as independent variables showed no significant association. In contrary, cross-sectional studies done on medical students in China and Brazil during this pandemic found significant associations between mental health disorders and place of residence, parental income/financial support, and gender (Cao et al. 2020; Sartorao Filho et al. 2020). Our results show that the response of the medical students to COVID-19 pandemic in terms of the levels of anxiety and stress is similar, irrespective of gender, year of study, current residence, and financial status of the family. Depression in the study population, on the other hand, remained unchanged during COVID-19 in all the categories except in male and urban population. Binary logistic regression showed that increase in age could decrease the likelihood of depression (OR $0.737,95 \% \mathrm{CI}$ 0.565-0.961) which is consistent to previous studies during COVID-19 (Ahmed et al. 2020a; González-Sanguino et al. 2020). However, in our study, the range of age was narrow (18-26 years) and mostly corresponded to the year of study, which had no significant association with depression. Hence, this observation becomes redundant. We found a significant increase in depression levels in male students but not in female students. This finding is contradictory to the study by Sartorao Filho et al., which found female medical students to be more at risk of developing depression symptoms during this pandemic (Sartorao Filho et al. 2020). Females are more proactive in their response and awareness about the epidemic when compared to males, and our results could be a possible implication of this (Brittni Frederiksen 2020). Despite higher levels of depression in the students from rural areas before COVID-19, their depression levels remained unchanged in the follow-up survey. However, the students from the urban areas presented with an increase in depression when compared to before COVID-19 levels. Nearly $53 \%$ of India's cases were recorded in Mumbai, Delhi, Ahmedabad, Pune, and Chennai alone, which were listed as top five COVID-19 cities (Shylendra 2020). Urban areas are highly populated, and the epidemic is more active in these areas than in rural areas. This led to the 
448 implementation of frequent lockdown measures by the respective State Governments in the 449 COVID-19 hotspots, which are mainly urban centers. This could have possibly increased the

450

451

452

453

454

455

456

457

458

459

460

461

462

463

464

465

466

467

468

469

470

471

472

473

474

475

476

477

478

479

480

481

482

483

484

485

486

487 psychological distress in the students from urban locations.

Since we did not find significant differences in mental health among most of the groups of demographic variables in both baseline and follow-up survey, it is likely that the worsening of mental health status of the medical students found in our study is associated with COVID-19related factors. To further elucidate this, we used adjusted binary logistic regression analysis to explore possible predictors. Our extensive literature survey showed all the collected demographic variables to have a potential influence on the outcome. Hence, despite not finding significant associations between demographics and mental health, we adjusted the effects of each potential predictor for all the recorded demographic variables in the regression models (Cao et al. 2020; Sartorao Filho et al. 2020; Heinze \& Dunkler 2017)

An important finding in our study is the independent bidirectional association between poor sleep quality and mental health. In our study, $34.6 \%$ of the study population suffered from poor sleep quality which was found to be a significant independent predictor of depression (aOR 1.337, 95\% CI 1.19-1.502), anxiety (aOR 1.227, 95\% CI 1.106-1.363) and stress (aOR 1.371, 95\% CI 1.209-1.555) during COVID-19 (Figures 5-7), similar to a previous study by Cellini $\mathrm{N}$ et al., in Italy (Cellini et al. 2020). Medical students are especially prone to poor sleep quality because of the physically and emotionally challenging and intense training they undertake (Wong et al. 2005). Poor sleep affects neurocognitive and psychomotor performance, emotional wellbeing, working capacity, academic performance, physical and mental health as well as quality of life (Al-Khani et al. 2019; Flores 2009; Giri et al. 2013; Mume et al. 2011). Due to lockdown measures and travel restrictions, students are facing decreased physical activity, lack of schedule, altered living conditions, increased screen time and time spent in social media, and altered sleep wake schedule including increased daytime nap duration (Majumdar et al. 2020). All these factors in addition to higher demands of medical curriculum could lead to poor sleep, which in turn affects mental wellbeing. Conversely, we also found that higher depression (aOR $1.114,95 \%$ CI 1.07-1.159), anxiety (aOR 1.120, 95\% CI 1.065-1.178) and stress levels (aOR $1.126,95 \%$ CI 1.078-1.176) during COVID-19 were significant predictors of poor sleep quality (Figure 4). Poor sleep is long since been considered an important symptom of mental health disorders. Sleep disturbance is a primary symptom of major depressive disorder (Jindal \& Thase 2004). Anxiety and stress negatively affect the body's ability to fall and stay asleep (Coplan et al. 2015; Kalmbach et al. 2018). In addition, increased time spent in social media and digital devices is a way by which young adults cope with social isolation, and it is associated with increased tendencies to develop sleep disturbances (Sivertsen et al. 2019). Thus, our findings show that poor sleep quality is both a cause and an effect of increased depression, anxiety, and stress symptoms in medical students during this pandemic. Thus, worsening of one could exacerbate the other. 
488 Students with higher baseline levels of depression, anxiety, and stress were found to be more 489 likely to have depression (aOR 1.27, 95\% CI 1.185-1.361), anxiety (aOR 1.176, 95\% CI 1.099490 1.259) and stress (aOR 1.810, 95\% CI 1.483-2.208) during COVID-19 outbreak (Figures 5-7). 491 There was also significant positive correlation between baseline and follow-up depression, 492 anxiety, and stress scores (Table 3). These results are consistent with a similar study conducted 493 on college students in China ( $\mathrm{Li}$ et al. 2020a). Studies show associations between pre-existing 494 mental health problems and mental health disorders in medical students (Yates et al. 2008). 495 Previous studies indicate that COVID-19 has a higher negative impact on people with mental health disorders when compared to those without any (Asmundson et al. 2020; Taylor et al. 2020). Medical students are proven to be at a higher risk of developing mental health disorders during the course of their training period (Moffat et al. 2004). With the added stressors related to

500 the pandemic, it might be difficult to cope, especially for those students who had higher levels of depression, anxiety, and stress to begin with, leading to exacerbation of symptoms.

501

502

503

A surprising finding in our study was that COVID-19-related academic apprehensions were not

504

505

506

507

508

509

510

511

512

513

514

515

516

517

518

519

520

521

522

523

524

525

526

527 significantly associated with depression, anxiety, and stress. This is in contrary to a recent study conducted in medical students in China, which found moderate positive correlation between worries about academic delay and anxiety (Cao et al. 2020). Although social desirability response bias could be an attributing factor, our finding could be a reflection of the feel of assurance by the students because of drastic student-centered efforts taken by the medical college and universities in continuing medical education. Another reason could be that, since these lockdown instigated changes were in effect for around three months, the students would have adapted to this new normalcy in their training better than anticipated. On the other hand, higher COVID-19-GA scores were found to be a significant predictor for higher levels of anxiety (aOR 1.097, 95\% CI 1.018-1.182) and stress (aOR 1.128, 95\% CI 1.037-1.227) (Figures 6, 7). In a study conducted on medical students in Pakistan, around $76 \%$ of the participants conveyed being worried about contracting COVID-19 during clinical postings and even more worried about insufficient care and improper treatment, if they contracted the infection (Ahmed et al. 2020b). In a recent study conducted on adult Indian population, individuals with increased self-perceived risk of contracting COVID-19 were found to be more likely to have mental health disorders (Saikarthik et al. 2020). A longitudinal study conducted in China in college students, found fear of infection to be significantly associated with anxiety and depression (Li et al. 2020a). Our results demonstrated that medical students' self-perceived levels of worries for the self, family, and friends about contracting COVID-19; surviving if contracted with COVID-19; and COVID19 affecting interpersonal relationships have a negative impact on their mental health. Student population is highly active in social media, which is filled with high amounts of misinformation, adding fear, and affecting mental well-being. Frequent use of social media was associated with higher prevalence of mental health problems during COVID-19 (Gao et al. 2020). At the same time, social media could be used for communications among peers and family, thereby offering much needed social support. 
528 In this study, we found no significant association between being tested for COVID-19 and 529 depression, anxiety, and stress. The possible reason could be that all of those who got tested for 530 COVID-19 were found negative. We also found that students without any COVID-19 patients 531 among their family and friends (aOR $0.259,95 \%$ CI $0.069-0.968$ ) and those who were not sure 532 about having any direct interactions with COVID-19 patients (aOR 0.280 95\% CI 0.092-0.856) 533 were found to be less likely to have symptoms of stress (Figure 7). Students without any direct 534 interactions with COVID-19 patients were less likely to have symptoms of depression (aOR 0.31 535 95\% CI 0.106-0.905) (Figure 5) when compared to those who did. These findings were in line 536 with the study by Cao et al. in China (Cao et al. 2020). The R naught (R0) of SARS-CoV-2 is 2.2 537 (2-2.5), i.e. each infected person spreads the infection to 2.2 individuals, in other words it is more

538

539

540

541

542

543

544

545

546

547

548

549

550

551

552

553

554

555

556

557

558

559

560

561

562

563

564

565

566

567 contagious than seasonal flu (Li et al. 2020b). This high contagious nature of the novel SARSCoV-2 virus could be related to our findings.

\section{Strengths and Limitations of the study}

The longitudinal nature of this study is its major strength which outweighs the limitation of relatively small sample size. The study investigated the mental health status of the same medical students before and during COVID-19 pandemic, which enabled in studying the pattern, temporal order and predictors of changes in their mental health status. To our knowledge, this is the first study to analyze the effects of COVID-19 outbreak on the mental health of undergraduate medical students longitudinally. We elaborately studied the influence of demographic variables, stressors related to COVID-19 by categorizing them into general and academic apprehensions as well as sleep quality, on mental health. With the known impact of negative mental health on medical students' career and life, we believe the results of our study is important due to the insights provided, that will help the medical educators to address and devise strategies to overcome the pandemic-induced negative impact on undergraduate medical students' mental health.

Our study is not without limitations. Though our study population includes students who were tested for COVID-19, none turned out positive. Thus, our results cannot be extrapolated to medical students infected with the virus. Despite promising confidentiality, there could have been possible response bias by the students in answering the survey.

\section{Conclusions}

Prevalence and levels of anxiety and stress increased, and depression symptoms remained unaltered during COVID-19 outbreak and quarantine. Poor sleep quality, higher levels of depression, anxiety, and stress before COVID-19, increased worries for the self, family, and friends about contracting and surviving, if contracted with COVID-19, and about COVID-19 affecting interpersonal relationships, presence of COVID-19 patients in family and friends and direct interactions with COVID-19 patients were found to be significant predictors of negative mental health in medical students. 
568 Neglecting the mental health of the medical students would lead to long-term detrimental effects, 569 which not only will affect the quality of life of medical students and future physicians, but also 570 the overall performance of the healthcare system. An effective plan to safeguard the mental 571 health of this already vulnerable population of undergraduate medical students is crucial. We 572 strongly believe our findings would help the medical educators in addressing and mitigating the 573 rise in mental health disorders, which could prove worse than the current pandemic itself. Further 574 studies to analyze the temporal pattern of changes in mental health status of the medical students 575 are warranted.

576

577

578

579

580

581

582

583

584

585

586

587

588

589

590

591

592

593

594

595

596

597

598

599

600

601

602

603

604

605

606

\section{Acknowledgements}

The authors would like to thank the Deanship of Scientific Research, Majmaah University, Kingdom of Saudi Arabia for academic support with the project number XXXX XXXX. The authors would also like to thank all the students for actively taking part in this study.

\section{Reference}

Agargun M, and Kara, Solmaz. 1997. Sleep disturbances and suicidal behavior in patients with major depression. The Journal of clinical psychiatry. 58:245-251.

Agarwal V, Gupta L, Davalbhakta S, Misra D, Agarwal V, and Goel AJ. 2020.

Undergraduate medical students in India are underprepared to be the young-taskforce against Covid-19 amid prevalent fears. medRxiv

Ahmed MZ, Ahmed O, Aibao Z, Hanbin S, Siyu L, and Ahmad AJ. 2020a. Epidemic of COVID-19 in China and associated Psychological Problems. Asian journal of psychiatry. 102092.

Ahmed N, Khan A, Naveed HA, Moizuddin SM, and Khan J. 2020b. Concerns of undergraduate medical students towards an outbreak of COVID-19. International Journal of Current Medical And Pharmaceutical Research. 6(3): 5055-62

Al-Khani AM, Sarhandi MI, Zaghloul MS, Ewid M, and Saquib NJ. 2019. A cross-sectional survey on sleep quality, mental health, and academic performance among medical students in Saudi Arabia. BMC research notes. 12(1):665.

Asmundson GJ, Paluszek MM, Landry CA, Rachor GS, McKay D, and Taylor SJ. 2020. Do pre-existing anxiety-related and mood disorders differentially impact COVID-19 stress responses and coping? Journal of Anxiety Disorders. 102271.

Bao Y, Sun Y, Meng S, Shi J, and Lu LJTL. 2020. 2019-nCoV epidemic: address mental health care to empower society. The Lancet. 395:e37-e38.

Batawi S, Tarazan N, Al-Raddadi R, Al Qasim E, Sindi A, Johni SA, Al-Hameed FM, Arabi YM, Uyeki TM, Alraddadi. 2019. Quality of life reported by survivors after hospitalization for Middle East respiratory syndrome (MERS). Health and quality of life outcomes. 17(1):1-7. 
607 Bergmann C, Muth T, and Loerbroks AJ. 2019. Medical students' perceptions of stress due to

608

609

610

611

612

613

614

615

616

617

618

619

620

621

622

623

624

625

626

627

628

629

630

631

632

633

634

635

636

637

638

639

640

641

642

643

644

645

academic studies and its interrelationships with other domains of life: a qualitative study. Medical education online. 24:1603526.

Brittni Frederiksen IG, Alina Salganicoff, and Usha Ranji. 2020. Coronavirus: A Look at Gender Differences in Awareness and Actions. Kaiser Family Foundation-Women's Health

Policy. Available at https://www.kff.org/coronavirus-covid-19/issue-brief/coronavirus-a-look-atgender-differences-in-awareness-and-actions/ (accessed 28 July 2020).

\section{Brooks SK, Webster RK, Smith LE, Woodland L, Wessely S, Greenberg N, and Rubin GJ.}

2020. The psychological impact of quarantine and how to reduce it: rapid review of the evidence. The Lancet. 395 (10227); 912-20

\section{Buysse DJ, Reynolds CF, Monk TH, Berman SR, and Kupfer DJ. 1989. The Pittsburgh}

Sleep Quality Index: a new instrument for psychiatric practice and research. Psychiatry research. 28:193-213.

Cao W, Fang Z, Hou G, Han M, Xu X, Dong J, and Zheng J. 2020. The psychological impact of the COVID-19 epidemic on college students in China. Psychiatry research. 112934.

Cellini N, Canale N, Mioni G, and Costa SJ. 2020. Changes in sleep pattern, sense of time and digital media use during COVID-19 lockdown in Italy. Journal of Sleep Research. e13074.

Chen R, Chou K-R, Huang Y-J, Wang T-S, Liu S-Y, and Ho L-YJ. 2006. Effects of a SARS prevention programme in Taiwan on nursing staff's anxiety, depression and sleep quality: a longitudinal survey. International journal of nursing studies. 43(2):215-225.

Cheung T, Yip PS. 2015. Depression, anxiety and symptoms of stress among Hong Kong nurses: a cross-sectional study. International journal of environmental research and public health. 12(9):11072-11100.

Chew-Graham CA, Rogers A, and Yassin N. 2003. 'I wouldn't want it on my CV or their records': medical students' experiences of help-seeking for mental health problems. Medical education. 37(10):873-880.

Choi B, Jegatheeswaran L, Minocha A, Alhilani M, Nakhoul M, and Mutengesa E. 2020. The impact of the COVID-19 pandemic on final year medical students in the United Kingdom: a national survey. BMC medical education. 20(1):1-11.

Coplan JD, Aaronson CJ, Panthangi V, and Kim YJ. 2015. Treating comorbid anxiety and depression: Psychosocial and pharmacological approaches. World journal of psychiatry. 5(4):366.

Crawford JR, and Henry JD. 2003. The Depression Anxiety Stress Scales (DASS): Normative data and latent structure in a large non-clinical sample. British journal of clinical psychology. 42(2):111-131.

Fawzy M, and Hamed SA. 2017. Psychological stress among medical students in Assiut University, Egypt. Psychiatry Research. 255 (10.1016).

Ferrel MN, and Ryan. 2020. The impact of COVID-19 on medical education. Cureus. 12(3) Flores SJ. 2009. Sleepiness or excessive daytime somnolence. Geriatric Nursing. 30 (1):53-60.

Peer) reviewing PDF | (2020:08:51660:2:0:NEW 18 Sep 2020) 
646 Gao J, Zheng P, Jia Y, Chen H, Mao Y, Chen S, Wang Y, Fu H. 2020. Mental health

647 problems and social media exposure during COVID-19 outbreak. Plos One. 15(4):e0231924.

648 Giri P, Baviskar M, Phalke D. 2013. Study of sleep habits and sleep problems among medical 649 students of Pravara Institute of Medical Sciences Loni, Western Maharashtra, India. Annals of 650 medical and health sciences research. 3(1):51-54.

651 González-Sanguino C, Ausín B, Ángel Castellanos M, Saiz J, López-Gómez A, Ugidos C, 652 Muñoz M. 2020. Mental health consequences during the initial stage of the 2020 Coronavirus 653 pandemic (COVID-19) in Spain. Brain, Behavior, and Immunity. 87: 172-176

654 Hays LR, Cheever T, and Patel P. 1996. Medical student suicide, 1989-1994. American 655 journal of psychiatry. 153 (4):553-555.

656 Heinze G, and Dunkler D. 2017. Five myths about variable selection. Transplant International. $65730(1): 6-10$.

658 Hill R. 1998. What sample size is "enough" in internet survey research. Interpersonal

659 Computing and Technology: An electronic journal for the 21st century. 6(3):1-12.

660 Huckins JF, DaSilva AW, Wang W, Hedlund E, Rogers C, Nepal SK, Wu J, Obuchi M, 661 Murphy EI, and Meyer ML. 2020. Mental health and behavior of college students during the 662 early phases of the COVID-19 pandemic: Longitudinal smartphone and ecological momentary 663 assessment study. Journal of medical Internet research. 22(6):e20185.

664 Jindal RD, and Thase ME. 2004. Treatment of insomnia associated with clinical depression. 665 Sleep medicine reviews. 8(1):19-30.

666 Johal SS. 2009. Psychosocial impacts of quarantine during disease outbreaks and interventions 667 that may help to relieve strain. NewZealand Medical Journal. 122 (1296):47 - 52

668 Kalmbach DA, Anderson JR, and Drake CL. 2018. The impact of stress on sleep: Pathogenic 669 sleep reactivity as a vulnerability to insomnia and circadian disorders. Journal of sleep research. 670 27(6):e12710.

671 Khasawneh AI, Humeidan AA, Alsulaiman JW, Bloukh S, Ramadan M, Al-Shatanawi TN, 672 Awad HH, Hijazi WY, Al-Kammash KR, Obeidat N, Saleh T, and Kheirallah KA. 2020.

673 Medical Students and COVID-19: Knowledge, Attitudes, and Precautionary Measures. A

674 Descriptive Study from Jordan. Frontiers in public health. 8: 253

675 Kumar SG, Kattimani S, Sarkar S, and Kar SS. 2017. Prevalence of depression and its 676 relation to stress level among medical students in Puducherry, India. Industrial psychiatry

677 journal. 26(1):86-90

678 Lee AM, Wong JG, McAlonan GM, Cheung V, Cheung C, Sham PC, Chu C-M, Wong P-C, 679 Tsang KW, and Chua SE. 2007. Stress and psychological distress among SARS survivors 1 680 year after the outbreak. The Canadian Journal of Psychiatry.52(4):233-240.

681 Lee SM, Kang WS, Cho A-R, Kim T, and Park JK. 2018. Psychological impact of the 2015

682 MERS outbreak on hospital workers and quarantined hemodialysis patients. Comprehensive

683 psychiatry. 87:123-127. 
684 Li HY, Cao H, Leung DY, Mak YW. 2020a. The Psychological Impacts of a COVID-19

685

686

687

688

689

690

691

692

693

694

695

696

697

698

699

700

701

702

703

704

705

706

707

708

709

710

711

712

713

714

715

716

717

718

719

720

721

722

Outbreak on College Students in China: A Longitudinal Study. International Journal of Environmental Research and Public Health.17(11):3933.

Li Q, Guan X, Wu P, Wang X, Zhou L, Tong Y, Ren R, Leung KS, Lau EH, and Wong JY. 2020b. Early transmission dynamics in Wuhan, China, of novel coronavirus-infected pneumonia. England Journal of Medicine. 382:1199-120

Lotsch F, Schnyder J, Goorhuis A, Grobusch MP. 2017. Neuropsychological long-term sequelae of Ebola virus disease survivors-a systematic review. Travel medicine and infectious disease. 18:18-23.

Lovibond PF, Lovibond SH, and therapy. 1995. The structure of negative emotional states: Comparison of the Depression Anxiety Stress Scales (DASS) with the Beck Depression and Anxiety Inventories. Behaviour research and therapy. 33(3):335-343.

Lu Y-C, Shu B-C, Chang Y-Y. 2006. The mental health of hospital workers dealing with severe acute respiratory syndrome. Psychotherapy and psychosomatics.75(6):370-375.

Majumdar P, Biswas A, and Sahu S. 2020. COVID-19 pandemic and lockdown: cause of sleep disruption, depression, somatic pain, and increased screen exposure of office workers and students of India. Chronobiology International:1-10.

Matthews T, Danese A, Caspi A, Fisher HL, Goldman-Mellor S, Kepa A, Moffitt TE, Odgers CL, and Arseneault L. 2019. Lonely young adults in modern Britain: findings from an epidemiological cohort study. Psychological medicine. 49(2):268-277.

McAlonan GM, Lee AM, Cheung V, Cheung C, Tsang KW, Sham PC, Chua SE, and Wong JG. 2007. Immediate and sustained psychological impact of an emerging infectious disease outbreak on health care workers. The Canadian Journal of Psychiatry. 52(4):241-247.

Moffat KJ, McConnachie A, Ross S, and Morrison JM. 2004. First year medical student stress and coping in a problem-based learning medical curriculum. Medical education. 38(5):482-491.

Molodynski A, Lewis T, Kadhum M, Farrell SM, Lemtiri Chelieh M, Falcão De Almeida T, Masri R, Kar A, Volpe U, Moir F, Torales J, Castaldelli-Maia JM, Chau SWH, Wilkes C, and Bhugra D. 2020. Cultural variations in wellbeing, burnout and substance use amongst medical students in twelve countries. International Review of Psychiatry:1-6. $10.1080 / 09540261.2020 .1738064$

Mume CO, Olawale KO, and Osundina AF. 2011. Excessive daytime sleepiness, nocturnal sleep duration and psychopathology among Nigerian university students. South African Journal of Psychiatry. 17(4):108-111.

Newsdesk TH. 2020. Coronavirus India lockdown Day 167 updates | September 8, 2020. Available at https://www.thehindu.com/news/national/coronavirus-india-lockdown-september-82020-live-updates/article32548682.ece (accessed 12 September 2020).

Nguyen HT, Do BN, Pham KM, Kim GB, Dam HT, Nguyen TT, Nguyen TT, Nguyen YH, Sørensen K. 2020. Fear of COVID-19 Scale-Associations of Its Scores with Health Literacy

Peer) reviewing PDF | (2020:08:51660:2:0:NEW 18 Sep 2020) 
723 and Health-Related Behaviors among Medical Students. International Journal of Environmental 724 Research and Public Health. 17(11):4164.

725 O'connor, BP. 2000. SPSS and SAS programs for determining the number of components using 726 parallel analysis and Velicer's MAP test. Behavior research methods, instruments, \& computers. 727 32(3):396-402.

728 Page AC, Hooke GR, and Morrison DL. 2007. Psychometric properties of the Depression 729 Anxiety Stress Scales (DASS) in depressed clinical samples. British Journal of Clinical 730 Psychology. 46(3):283-297.

731 Pierce M, Hope H, Ford T, Hatch S, Hotopf M, John A, Kontopantelis E, Webb R, Wessely 732 S, and McManus SJ. 2020. Mental health before and during the COVID-19 pandemic: a 733 longitudinal probability sample survey of the UK population. The Lancet Psychiatry.

734 Rahe C, Czira ME, Teismann H, and Berger KJ. 2015. Associations between poor sleep 735 quality and different measures of obesity. Sleep medicine. 16(10):1225-1228.

736 Ren Y, Zhou Y, Qian W, Li Z, Liu Z, Wang R, Qi L, Yang J, Song X, Zeng L, and Zhang 737 X. 2020. Letter to the Editor "A longitudinal study on the mental health of general population 738 during the COVID-19 epidemic in China". Brain, behavior, and immunity. 87:132-133.

739 10.1016/j.bbi.2020.05.004

740 Reynolds DL, Garay J, Deamond S, Moran MK, Gold W, Styra R. 2008. Understanding, 741 compliance and psychological impact of the SARS quarantine experience. Epidemiology \& 742 Infection. 136(7):997-1007.

743 Rosenthal JM, and Okie SJ. 2005. White coat, mood indigo-depression in medical school. New 744 England journal of medicine. 353(11):1085.

745 Saikarthik J, Saraswathi I, and Siva T. 2020. Risk factors and protective factors of mental 746 health during COVID-19 outbreak and lockdown in adult Indian population-A cross-sectional 747 study. medRxiv

748 Sartorao Filho CI, Rodrigues WCdLV, de Castro RB, Marcal AA, Pavelqueires S, Takano 749 L, de Oliveira WL, and Neto CIS. 2020. Impact Of Covid-19 Pandemic On Mental Health Of 750 Medical Students: A Cross-Sectional Study Using GAD-7 And PHQ-9 Questionnaires. medRxiv 751 Schwenk TL, Davis L, and Wimsatt LA. 2010. Depression, Stigma, and Suicidal Ideation in 752 Medical Students. JAMA.304(11):1181-1190.

753 Shad R, Thawani R, and Goel A. 2015. Burnout and sleep quality: a cross-sectional 754 questionnaire-based study of medical and non-medical students in India. Cureus. 7(10)

755 Shylendra H. 2020. How is Covid-19 playing out in rural India? Available at

$756 \mathrm{https}$ ://www.thehindubusinessline.com/opinion/how-is-covid-19-playing-out-in-rural-

757 india/article31671013.ece (accessed 27 July 2020).

758 Sivertsen B, Vedaa O, Harvey AG, Glozier N, Pallesen S, Aarø LE, Lønning KJ, and

759 Hysing MJ. 2019. Sleep patterns and insomnia in young adults: a national survey of Norwegian 760 university students. Journal of sleep research. 28(2):e12790.

761 Stormon N, Ford PJ, Kisely S, Bartle E, and Eley DS. 2019. Depression, anxiety and stress in 762 a cohort of Australian dentistry students. European Journal of Dental Education. 23(4):507-514. 
763

764

765

766

767

768

769

770

771

772

773

774

775

776

777

778

779

780

781

782

783

784

785

786

787

788

789

790

791

792

793

794

795

796

797

798

799

Taghrir MH, Borazjani R, and Shiraly RJ. 2020. COVID-19 and Iranian Medical Students; A Survey on Their Related-Knowledge, Preventive Behaviors and Risk Perception. Archives of Iranian medicine. 23(4):249-254.

Tao S, Wu X, Zhang Y, Zhang S, Tong S, Tao FJ. 2017. Effects of sleep quality on the association between problematic mobile phone use and mental health symptoms in Chinese college students. International journal of environmental research and public health. 14(2):185. Taylor S. 2019. The psychology of pandemics: Preparing for the next global outbreak of infectious disease: Cambridge Scholars Publishing.

Taylor S, Landry CA, Paluszek MM, Fergus TA, McKay D, Asmundson GJ. 2020. COVID stress syndrome: Concept, structure, and correlates. Depression and anxiety. 37(8):706-714. The New York Times. The Coronavirus update: Skyrocketing cases push India to No. 2 on the pandemic list. Available at: https://www.nytimes.com/2020/09/07/world/covid-19coronavirus.html (Accessed on 12 September 2020)

Tian-Ci Quek T, Tam W-S, X Tran B, Zhang M, Zhang Z, Su-Hui Ho C, Chun-Man Ho R. 2019. The global prevalence of anxiety among medical students: a meta-analysis. International journal of environmental research and public health. 16(15):2735.

Wang C, Pan R, Wan X, Tan Y, Xu L, Ho CS, Ho R. 2020. Immediate psychological responses and associated factors during the initial stage of the 2019 coronavirus disease (COVID-19) epidemic among the general population in China. International journal of environmental research and public health. 17(15):1729.

WHO. 2009. World now at the start of 2009 influenza pandemic. Available at https://www.who.int/mediacentre/news/statements/2009/h1n1_pandemic_phase6_20090611/en/ (accessed 02 August 2020).

WHO. 2020. Archived: WHO Timeline - COVID-19. Available at https://www.who.int/newsroom/detail/27-04-2020-who-timeline---covid-19 (accessed 29 July 2020).

Wolf TM. 1994. Stress, coping and health: enhancing well-being during medical school. Medical education. 28(1):8-17. 10.1111/j.1365-2923.1994.tb02679.x

Wong J, Patil N, Beh S, Cheung E, Wong V, Chan L, and Lieh Mak F. 2005. Cultivating psychological well-being in Hong Kong's future doctors. Medical teacher. 27(8):715-719.

Wong TW, Gao Y, Tam WWS. 2007. Anxiety among university students during the SARS epidemic in Hong Kong. Journal of the International Society for the Investigation of Stress. 23(1):31-35.

Yadav R, Gupta S, and Malhotra AK. 2016. A cross sectional study on depression, anxiety and their associated factors among medical students in Jhansi, Uttar Pradesh, India. Int $J$ Community Med Public Health. 3(5):1209-1214.

Yates J, James D, and Aston I. 2008. Pre-existing mental health problems in medical students: a retrospective survey. Medical Teacher. 30(3):319-321. 10.1080/01421590701797630 


\section{Table $\mathbf{1}$ (on next page)}

Relationship between demographic variables and baseline and follow-up depression, anxiety and stress scores

${ }^{\text {a }} \mathrm{P}$ value: Wilcoxon signed rank test, ${ }^{\mathrm{b}} \mathrm{P}$ value: McNemar test, ${ }^{\mathrm{C}} \mathrm{P}$ value: Mann Whitney $\mathrm{U}$ test, ${ }^{\mathrm{d}} \mathrm{P}$ value: Chi square test, ${ }^{\mathrm{e}} \mathrm{P}$ value: Kruskal Wallis test, $\mathrm{r}$ value: effect size of Wilcoxon signed rank test

$\mathrm{N}(\%)$ : Number of subjects with depression, anxiety and stress

Subjects with depression: depression sub-score $>9$,

Subjects with anxiety: anxiety sub-score $>7$,

Subjects with stress: stress sub-score $>14$

Significant $\mathrm{P}$ value in bold letters 
Table 1: Relationship between demographic variables and baseline and follow-up depression, anxiety and stress scores

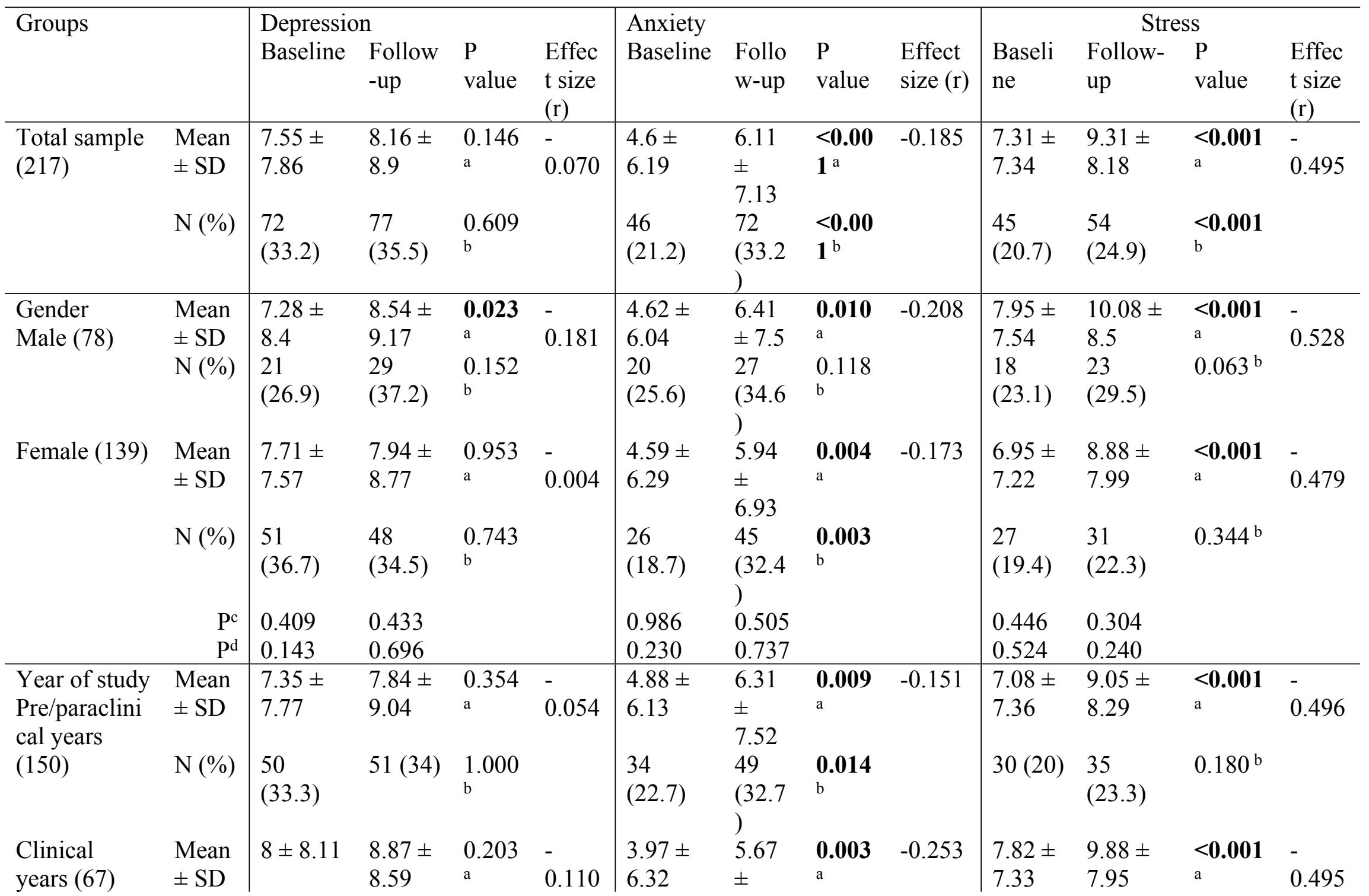




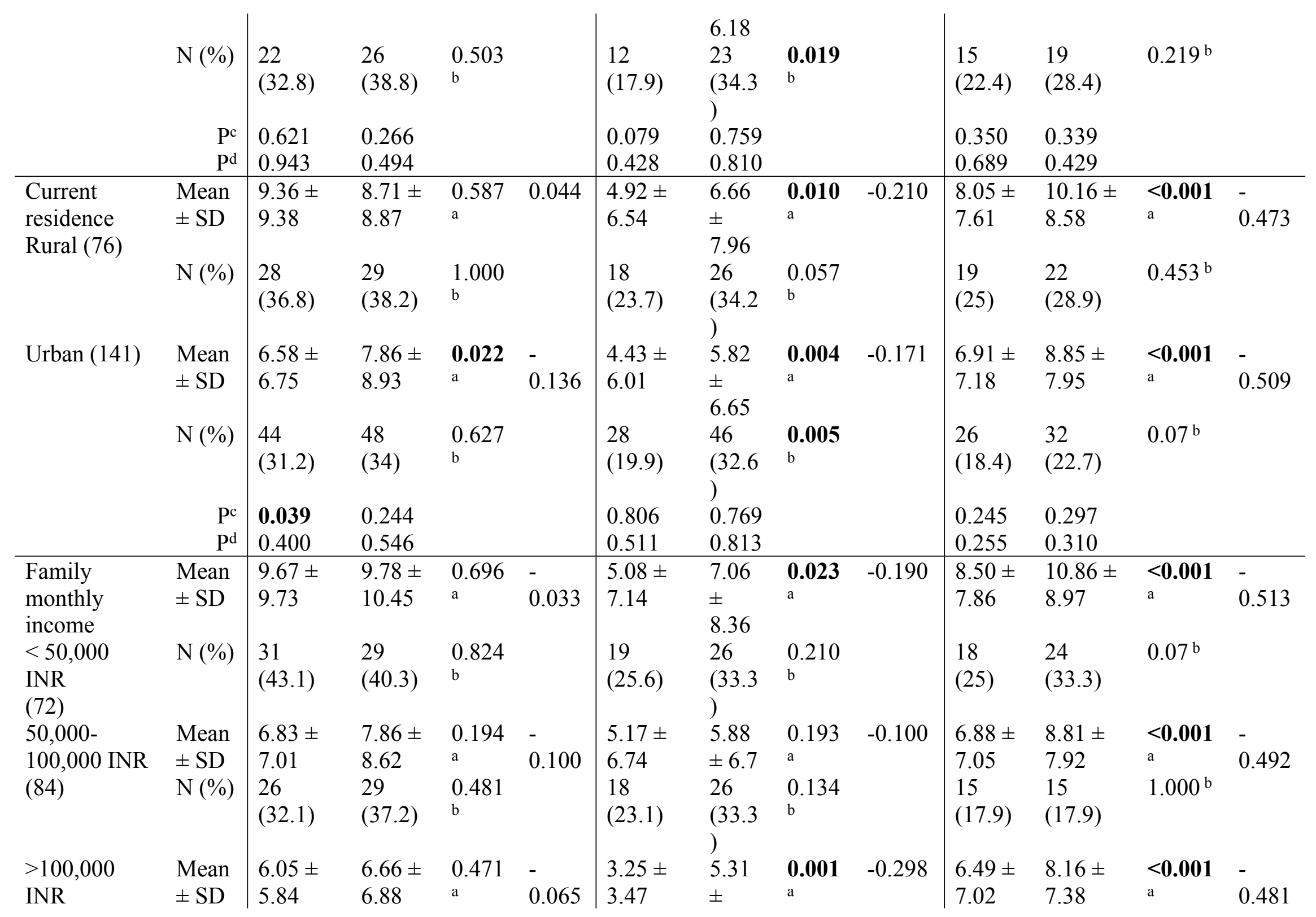


(61)

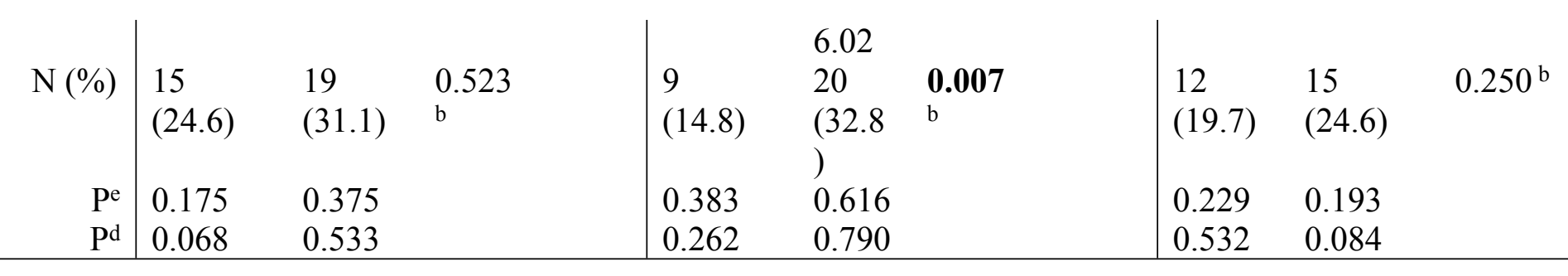

3

${ }^{a} \mathrm{P}$ value: Wilcoxon signed rank test, ${ }^{\mathrm{b}} \mathrm{P}$ value: McNemar test, ${ }^{\mathrm{c}} \mathrm{P}$ value: Mann Whitney $\mathrm{U}$ test, ${ }^{\mathrm{d}} \mathrm{P}$ value: Chi square test, ${ }^{\mathrm{e}} \mathrm{P}$ value:

5 Kruskal Wallis test, $r$ value: effect size of Wilcoxon signed rank test

$6 \quad \mathrm{~N}(\%)$ : Number of subjects with depression, anxiety and stress

7 Subjects with depression: depression sub-score $>9$,

8 Subjects with anxiety: anxiety sub-score $>7$,

9 Subjects with stress: stress sub-score $>14$

10 significant $\mathrm{P}$ value in bold letters 


\section{Table 2 (on next page)}

Difference in the ranks of DASS21 scores between baseline and follow-up surveys

${ }^{a}$ follow-up $<$ baseline ${ }^{b}$ follow-up $>$ baseline ${ }^{c}$ follow-up = baseline 
1 Table 2: Difference in the ranks of DASS21 scores between baseline and follow-up surveys 2

\begin{tabular}{|l|l|l|l|l|l|l|}
\hline $\begin{array}{l}\text { Score } \\
\text { difference }\end{array}$ & $\begin{array}{l}\text { Negative } \\
\text { Ranks } \\
(\mathrm{N})\end{array}$ & $\begin{array}{l}\text { Positive } \\
\text { Ranks }^{\mathrm{b}} \\
(\mathrm{N})\end{array}$ & $\begin{array}{l}\text { Ties }^{\mathrm{c}} \\
(\mathrm{N})\end{array}$ & \multicolumn{2}{|l|}{$\begin{array}{l}\text { Median score }\left(50^{\text {th }}\right. \\
\text { percentile }\end{array}$} & $\begin{array}{l}\text { Wilcoxon } \\
\text { signed-ra } \\
\text { saseline }\end{array}$ \\
& & & $\begin{array}{l}\text { Follow- } \\
\text { up } \\
\text { test } \\
\text { P-value }\end{array}$ \\
\hline Depression & 60 & 97 & 60 & 6 & 6 & 0.146 \\
\hline Anxiety & 69 & 89 & 59 & 2 & 4 & $<\mathbf{0 . 0 0 1}$ \\
\hline Stress & 7 & 142 & 68 & 6 & 8 & $<\mathbf{0 . 0 0 1}$ \\
\hline
\end{tabular}

3

$4 \quad{ }^{\mathrm{a}}$ follow-up $<$ baseline, ${ }^{\mathrm{b}}$ follow-up $>$ baseline, ${ }^{\mathrm{c}}$ follow-up $=$ baseline 


\section{Table 3 (on next page)}

Correlation between scores of survey instruments from baseline and follow-up survey

The results are expressed as $\rho$ (Rho) value; ( $\mathrm{P}<0.05)$; (** $\mathrm{P}<0.001)$ 
Table 3: Correlation between scores of survey instruments from baseline and follow-up survey

\begin{tabular}{|c|c|c|c|c|c|c|c|c|c|}
\hline Variables & $\begin{array}{l}\text { COVID-19- } \\
\text { AA }\end{array}$ & $\begin{array}{l}\text { COVID- } \\
\text { 19-GA } \\
\end{array}$ & PSQI & $\begin{array}{l}\text { Depression } \\
\text { (baseline) }\end{array}$ & $\begin{array}{l}\text { Depression } \\
\text { (follow-up) }\end{array}$ & $\begin{array}{l}\text { Anxiety } \\
\text { (baseline) }\end{array}$ & $\begin{array}{l}\text { Anxiety } \\
\text { (follow- } \\
\text { up) }\end{array}$ & $\begin{array}{l}\text { Stress } \\
\text { (baseline) }\end{array}$ & $\begin{array}{l}\text { Stress } \\
\text { (follow- } \\
\text { up) }\end{array}$ \\
\hline COVID-19-AA & 1.000 & - & - & - & - & - & - & - & - \\
\hline COVID-19-GA & $\begin{array}{l}-0.026 \\
(0.703)\end{array}$ & 1.000 & - & & - & - & - & - & - \\
\hline PSQI & $\begin{array}{l}0.030 \\
(0.664)\end{array}$ & $\begin{array}{l}0.032 \\
(0.638)\end{array}$ & 1.000 & & & _ & - & & - \\
\hline $\begin{array}{l}\text { Depression } \\
\text { (baseline) }\end{array}$ & $\begin{array}{l}-0.025 \\
(0.710)\end{array}$ & $\begin{array}{l}0.152 * \\
(0.025)\end{array}$ & $\begin{array}{l}0.422 * * \\
(<0.001)\end{array}$ & 1.000 & & - & - & 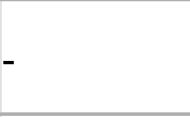 & _ \\
\hline $\begin{array}{l}\text { Depression } \\
\text { (follow-up) }\end{array}$ & $\begin{array}{l}0.019 \\
(0.782)\end{array}$ & $\begin{array}{l}0.072 \\
(0.292)\end{array}$ & $\begin{array}{l}0.520 * * \\
(<0.001)\end{array}$ & $\begin{array}{l}0.673 * * \\
(<0.001)\end{array}$ & 1.000 & & 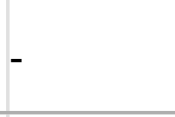 & & _ \\
\hline $\begin{array}{l}\text { Anxiety } \\
\text { (baseline) }\end{array}$ & $\begin{array}{l}-0.010 \\
(0.886)\end{array}$ & $\begin{array}{l}0.126 \\
(0.063)\end{array}$ & $\begin{array}{l}0.296 * * \\
(<0.001)\end{array}$ & $\begin{array}{l}0.566 * * \\
(<0.001)\end{array}$ & $\begin{array}{l}0.511 * * \\
(<0.001)\end{array}$ & 1.000 & _ & - & - \\
\hline $\begin{array}{l}\text { Anxiety (follow- } \\
\text { up) }\end{array}$ & $\begin{array}{l}0.012 \\
(0.857)\end{array}$ & $\begin{array}{l}0.088 \\
(0.199)\end{array}$ & $\begin{array}{l}0.389 * * \\
(<0.001)\end{array}$ & $\begin{array}{l}0.594 * * \\
(<0.001)\end{array}$ & $\begin{array}{l}0.712 * * \\
(<0.001)\end{array}$ & $\begin{array}{l}0.502 * * \\
(<0.001)\end{array}$ & 1.000 & & _ \\
\hline Stress (baseline) & $\begin{array}{l}0.011 \\
(0.873)\end{array}$ & $\begin{array}{l}0.130 \\
(0.055)\end{array}$ & $\begin{array}{l}0.474 * * \\
(<0.001)\end{array}$ & $\begin{array}{l}0.710 * * \\
(<0.001)\end{array}$ & $\begin{array}{l}0.783 * * \\
(<0.001)\end{array}$ & $\begin{array}{l}0.575 * * \\
(<0.001)\end{array}$ & $\begin{array}{l}0.765 * * \\
(<0.001)\end{array}$ & 1.000 & - \\
\hline $\begin{array}{l}\text { Stress (follow- } \\
\text { up) }\end{array}$ & $\begin{array}{l}-0.007 \\
(0.914)\end{array}$ & $\begin{array}{l}0.130 \\
(0.056)\end{array}$ & $\begin{array}{l}0.460 * * \\
(<0.001)\end{array}$ & $\begin{array}{l}0.690 * * \\
(<0.001)\end{array}$ & $\begin{array}{l}0.771 * * \\
(<0.001)\end{array}$ & $\begin{array}{l}0.571 * * \\
(<0.001)\end{array}$ & $\begin{array}{l}0.729 * * \\
(<0.001)\end{array}$ & $\begin{array}{l}0.961 * * \\
(<0.001)\end{array}$ & 1.000 \\
\hline
\end{tabular}

2 The results are expressed as $\rho$ (Rho) value; $(* \mathrm{P}<0.05) ;(* * \mathrm{P}<0.001)$ 


\section{Figure 1}

Flow chart illustrating the sample selection from baseline to follow-up

DASS21: Depression, Anxiety, Stress Scale 21 items.

PSQI: Pittsburgh Sleep Quality Index. 


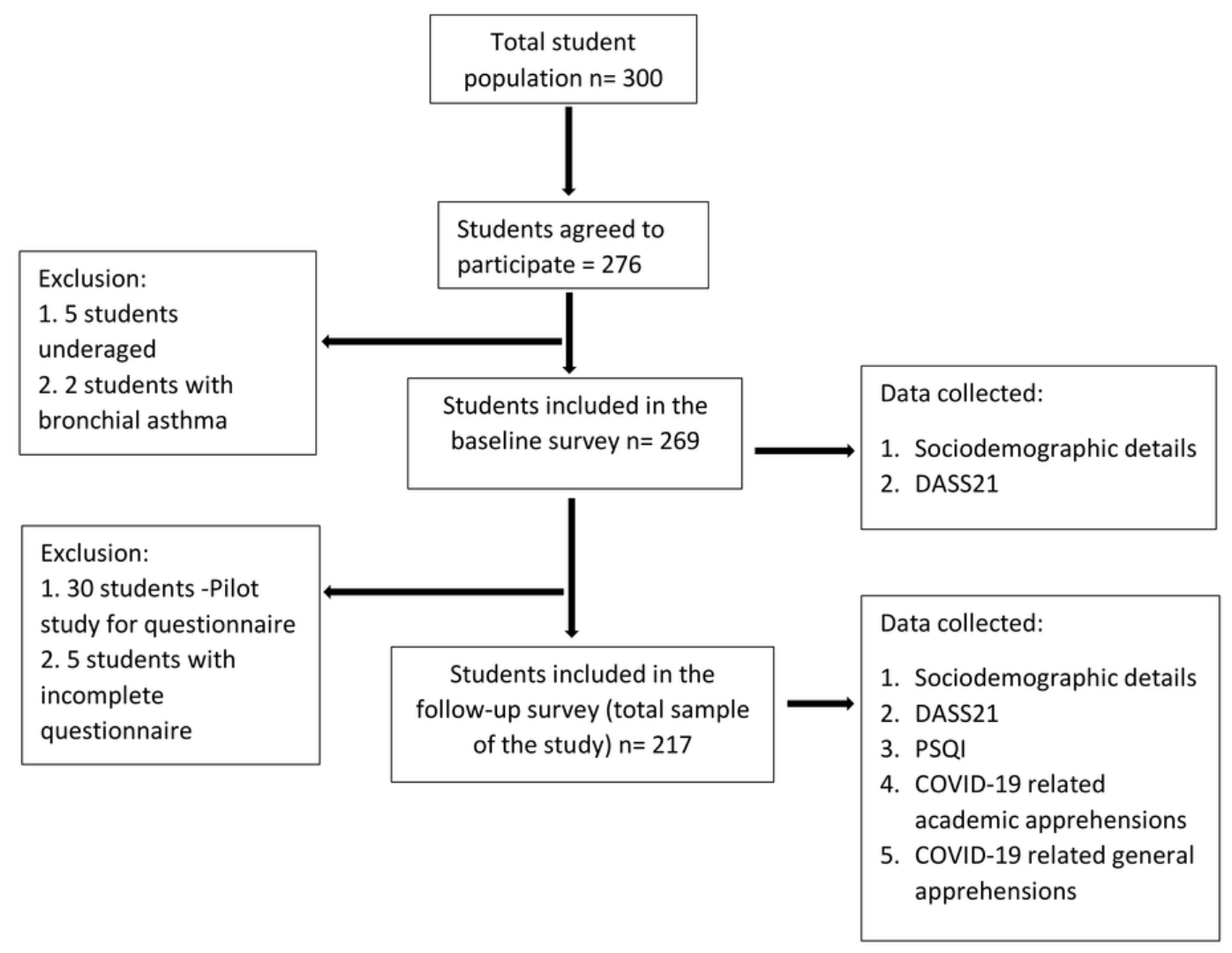


Figure 2

\section{Distribution of responses to self-administered questionnaire (in \%)}

Items 4 to 12: Likert scale score, 1 through 5; from minimum to maximum COVID-19-GA

scores $(5$ to 25$)=4+5+6+7+8) ;$ COVID-19-AA scores $(4$ to 20$)=9+10+11+12$

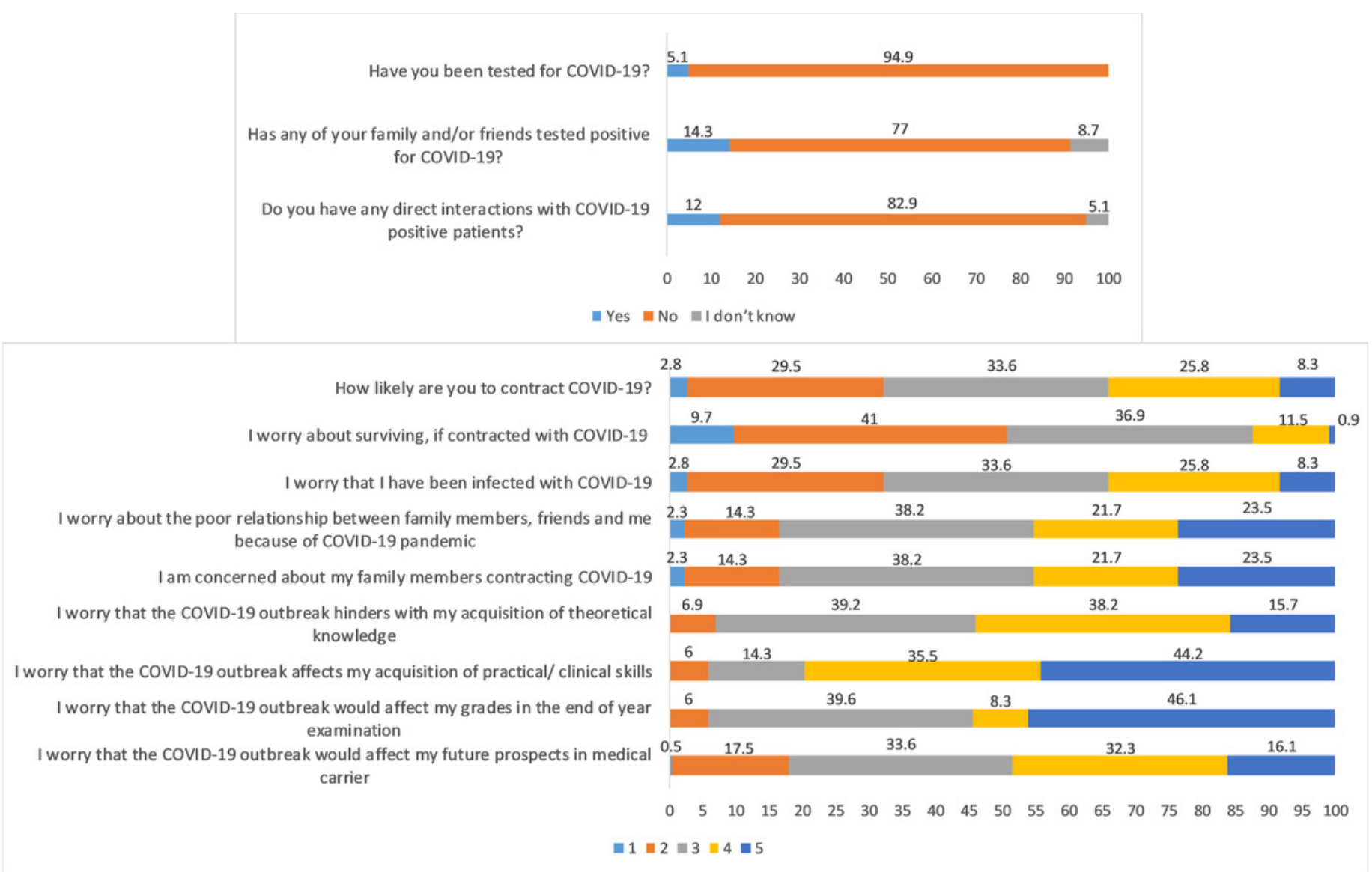




\section{Figure 3}

Percentage distribution of baseline and follow-up depression, anxiety and stress levels and sleep quality in follow-up survey

* Severity ranking scores DASS-42. Depression: normal; 0-9, mild. 10-13, moderate; 14-20, severe; 21-27, extremely severe $\geq 28$. Anxiety: normal; 0-7, mild; 8-9, moderate; 10-14, severe; 15-19, extremely severe $\geq 20$. Stress: normal; 0-14, mild; $15-18$, moderate; $19-25$, severe; $26-33$, extremely severe $\geq 34$. DASS21 mean scores are doubled to calculate severity ranking (Lovibond et al. 1995)

${ }^{* *}$ global PSQI score above 5 is considered to be poor sleep quality (Buysse et al. 1989)

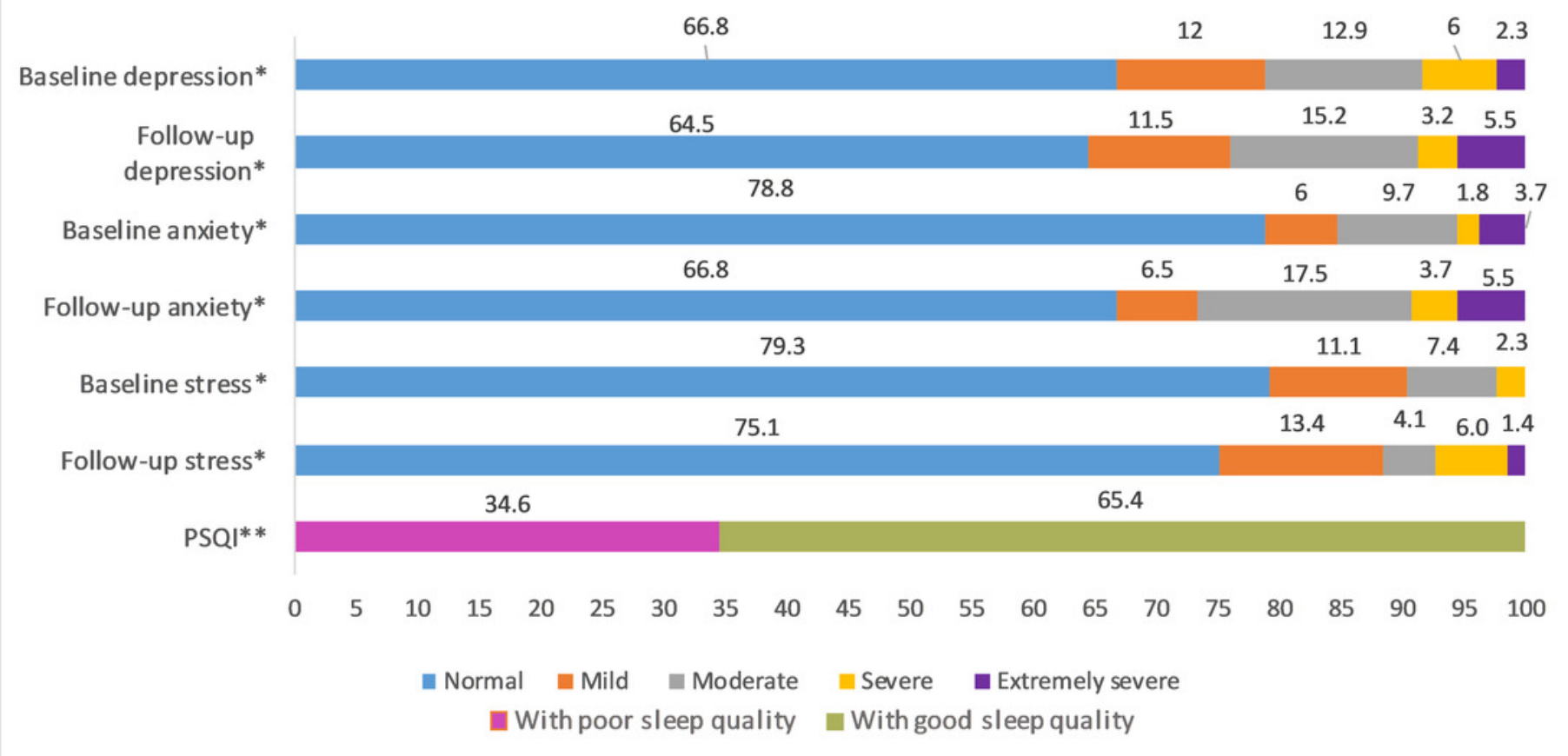


Figure 4

Forest plot showing adjusted binary logistic regression analysis of follow-up PSQI scores (cross sectional)

aOR adjusted odds ratio; odds ratio adjusted for age, gender, year of study, urban/rural residential status, family's monthly financial status; $95 \% \mathrm{Cl} 95 \%$ confidence interval;

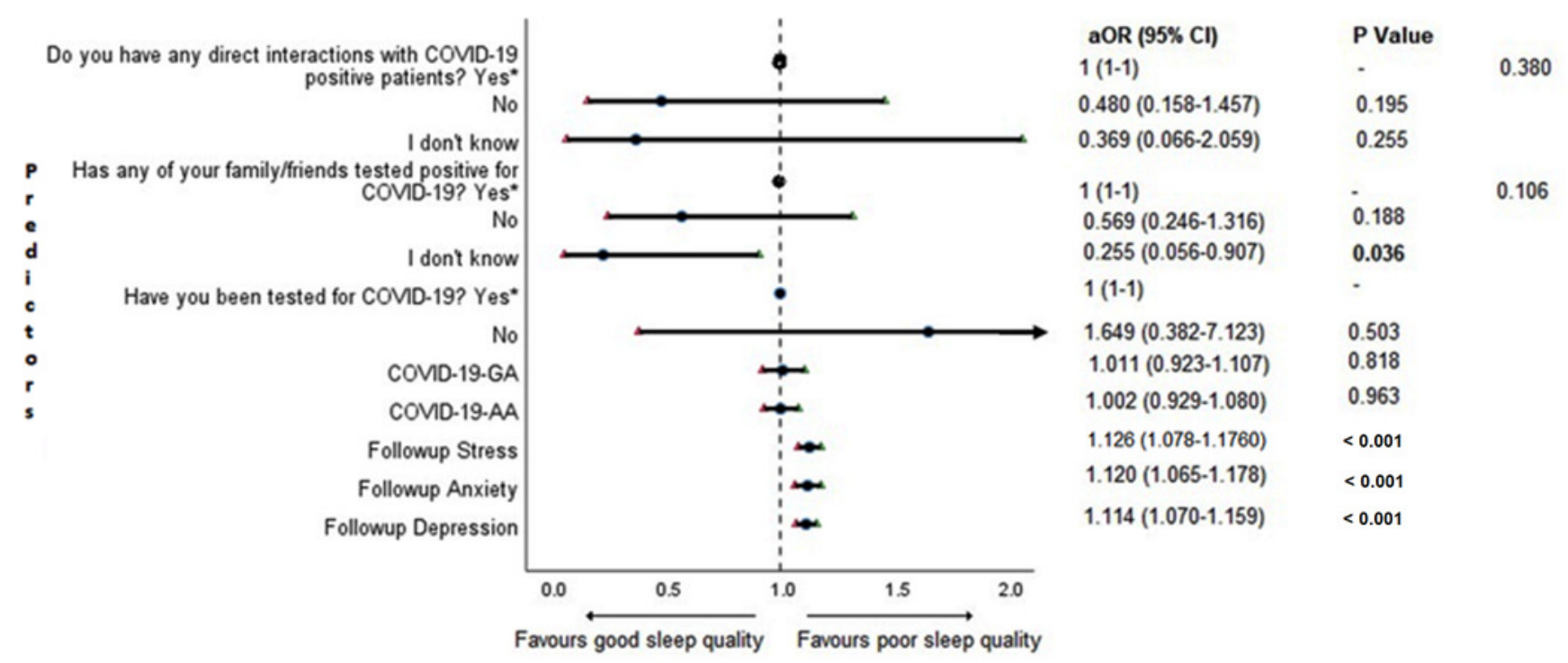


Figure 5

Forest plot showing adjusted binary logistic regression analysis of follow-up depression scores

aOR adjusted odds ratio; odds ratio adjusted for age, gender, year of study, urban/rural residential status, family's monthly financial status; $95 \% \mathrm{Cl} 95 \%$ confidence interval;

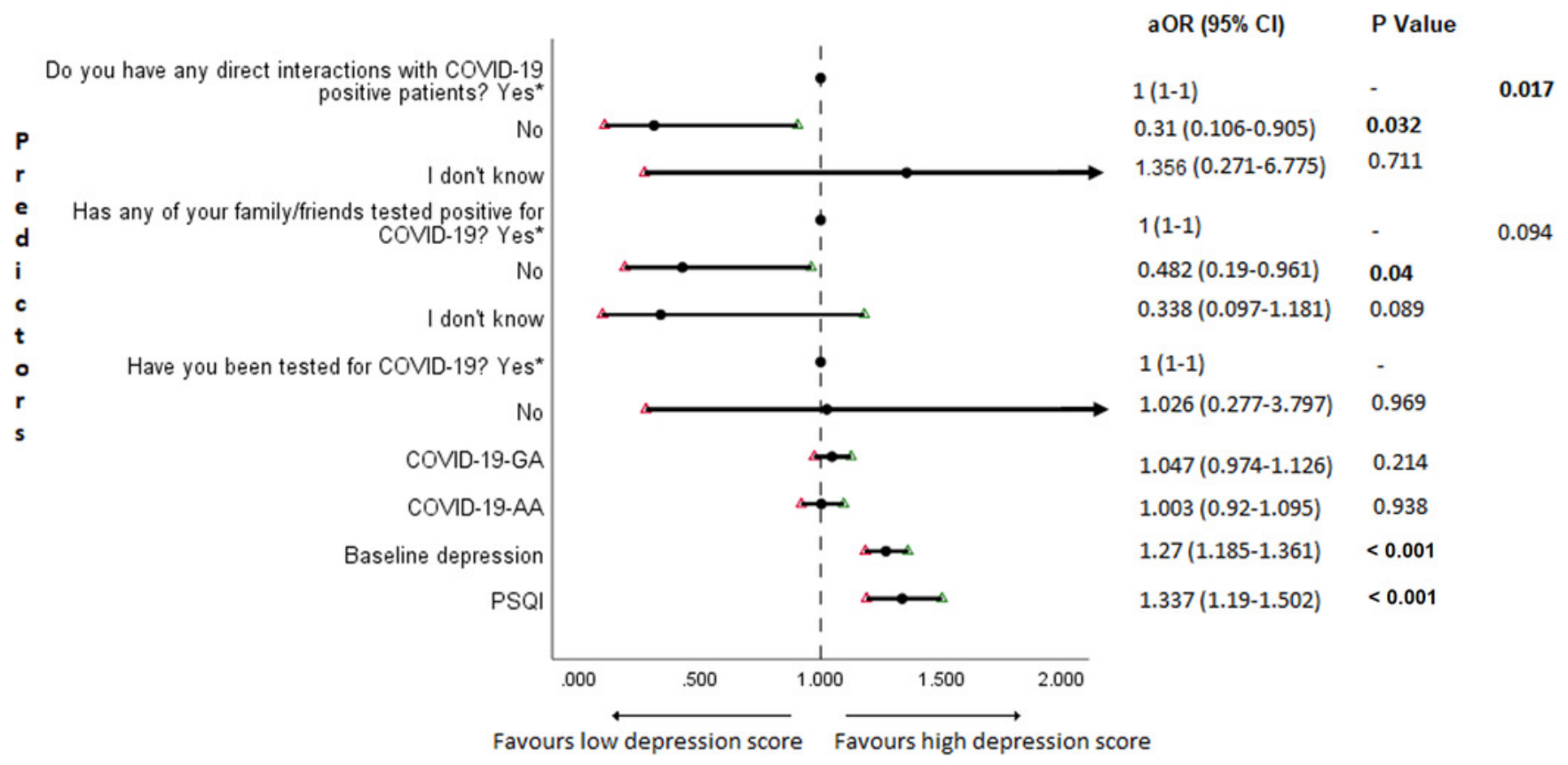




\section{Figure 6}

Forest plot showing adjusted binary logistic regression analysis of follow-up anxiety scores

aOR adjusted odds ratio; odds ratio adjusted for age, gender, year of study, urban/rural residential status, family's monthly financial status; $95 \% \mathrm{Cl} 95 \%$ confidence interval;

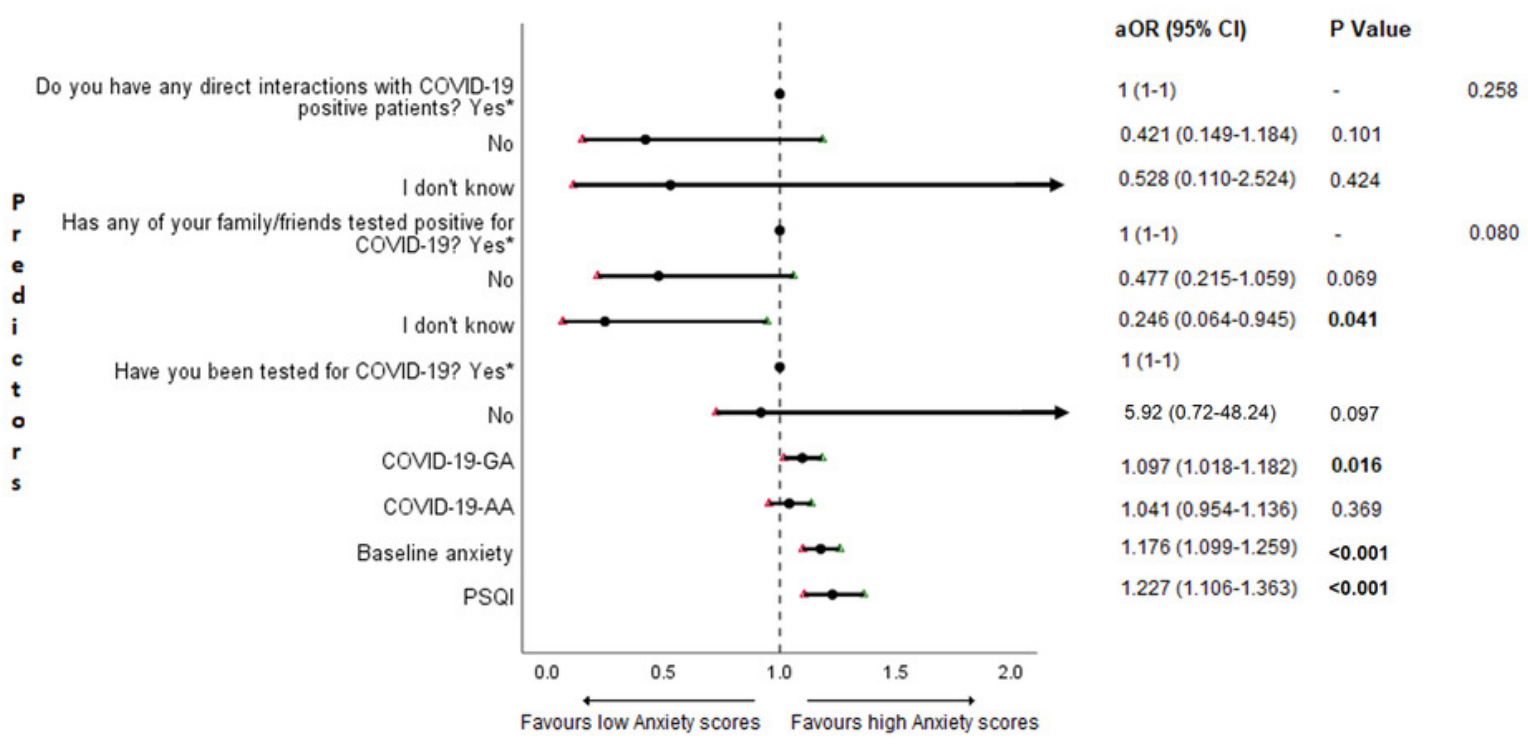


Figure 7

Forest plot showing adjusted binary logistic regression analysis of follow-up stress scores

aOR adjusted odds ratio; odds ratio adjusted for age, gender, year of study, urban/rural residential status, family's monthly financial status; $95 \% \mathrm{Cl} 95 \%$ confidence interval;

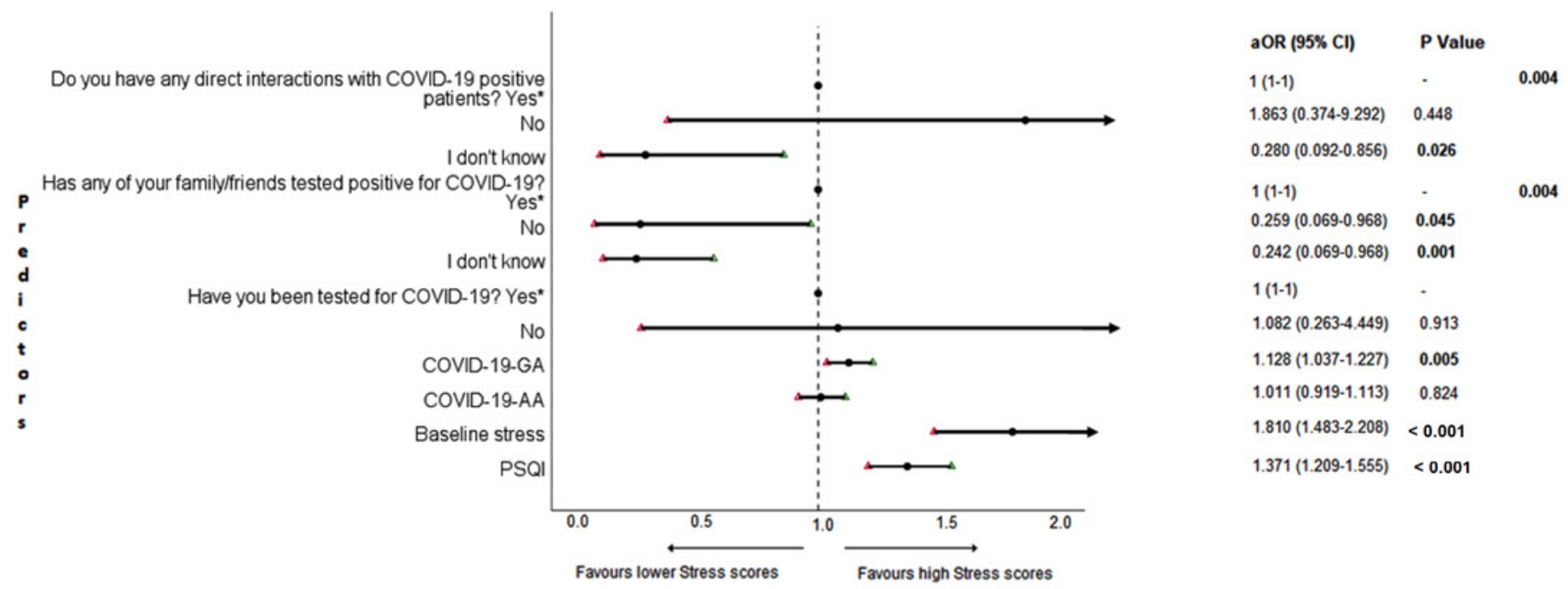

